\title{
Elastic local buckling of three-flanged cross-sections
}

\author{
Chunyan Quan, Andreas Fieber, Leroy Gardner* \\ Department of Civil and Environmental Engineering, Imperial College London, SW7 2AZ London, UK
}

\begin{abstract}
In current structural steel design specifications, the local buckling of cross-sections is typically treated on an element-by-element basis, with the boundary conditions along the adjoined longitudinal edges of the individual plates assumed to be simply-supported. In reality, cross-sections buckle locally as a whole and the individual plate elements interact. As a result, the boundary conditions along the adjoined longitudinal edges of the critical isolated plate (i.e. that with the lowest elastic local buckling stress) lie between lower and upper bounds of simplysupported and fixed, respectively. Based on this concept, explicit formulae to predict the elastic local buckling stress of full cross-sections of common profiles, including I-sections, have recently been developed [1]. In the present paper, the formulae for single I-sections set out in [1] are extended to cover the case of three-flanged cross-sections that arise in longitudinallystiffened plate girders and in the haunch and apex regions of portal frames. The geometry and loading of the studied cross-sections are assumed to remain constant along the member length, i.e. the influence of tapering and moment gradients on local buckling are not considered herein, but has been evaluated in parallel work [2]. The proposed formulae are calibrated against results from finite strip analysis performed using CUFSM v4.05 [3] on a range of three-flanged sections, and provide predictions of elastic local buckling stresses that are typically within 5\% of the numerically obtained values.
\end{abstract}

Keywords: CUFSM; Elastic local buckling; Element interaction; Local instability; Plate buckling; Portal frames; Three-flanged cross-sections. 


\section{Introduction}

There are a number of scenarios in which structural members with cross-sections having three flanges are utilised in practice, including in longitudinally-stiffened plate girders (see Fig. 1(a)) and in the haunch and apex regions of portal frames (see Figs. 1(b) and (c)). In the former case, the members are prismatic and the formulae developed herein are directly applicable. In the latter case, the members are tapered and account should be taken of the variation in crosssection geometry along the member length; the authors have explored [2] the approach of initially neglecting tapering effects at the cross-section level in the determination of the elastic local buckling stress, then allowing for the variation in cross-section properties at the global member level through geometrically and materially nonlinear analysis using beam finite elements with stepped properties along the member length. This is analogous to the current practice of classifying and determining effective section properties for individual crosssections without considering either the member length or the gradient of forces or cross-section geometry along the member length [4]. Following this approach, the resulting resistance predictions have been shown to be extremely accurate in comparison to shell finite element results, confirming the validity of the approach up to tapering angles of $15^{\circ}$ [2].

In current steel design specifications, such as EN 1993-1-1 [4] and AISC 360-16 [5], the resistance and deformation capacity of structural cross-sections are determined with reference to the concept of cross-section classification, whereby limiting width-to-thickness ratios for the individual cross-section plates (assuming simply-supported boundary conditions along their adjoined edges) are defined to assess the extent to which local buckling influences the behaviour of the full cross-section. In reality, the plate elements within a cross-section interact with each other and enhanced cross-section capacities can be exploited when element interaction is explicitly considered. Recently established design methods, such as the Direct Strength Method (DSM) [6,7] and the Continuous Strength Method (CSM) [8-10], are able to 
account for the beneficial effects of element interaction by using the elastic local buckling stress of the full cross-section to determine the cross-section slenderness and hence the crosssection resistance. While there has been a number of studies into the effects of element interaction on the elastic local buckling response of single I-sections [1,11-17], no studies have, to the knowledge of the authors, considered the effect of element interaction in three-flanged sections.

In the present paper, the formulae for calculating the elastic local buckling stress of single Isections subjected to combined compression and major axis bending developed in [1] are extended to three-flanged sections. Note that although three-flanged section members are, when used in the eaves and apex regions of portal frames, typically tapered and subjected to moment gradients, the cross-sectional behaviour is the focus of the present study, i.e. the elastic local buckling response of uniformly-loaded prismatic members with three-flanged crosssections is examined. The influence of tapering [18-22] and moment gradients [23-25] have been investigated elsewhere at the member level [2]. The predicted elastic local buckling stresses are compared with results obtained from finite strip analysis performed using CUFSM [3] and with elastic buckling stresses calculated on an element-by-element basis (i.e. ignoring the influence of element interaction). Finally, implementation of the developed expressions is demonstrated through a worked example.

\section{Elastic local buckling of plates and I-sections}

\subsection{Elastic buckling of isolated plates}

The elastic local buckling stress $\sigma_{\mathrm{cr}, \mathrm{p}}$ of a rectangular flat plate of width $b$ and thickness $t$, made of an elastic material with Young's modulus $E$ and Poisson's ratio $v$, is given by Eq. (1), where the plate buckling coefficient $k$ depends on three principal factors: (1) the plate aspect ratio, (2) 
the restraint conditions along the plate edges and (3) the distribution of axial stress applied to the plate.

$$
\sigma_{\mathrm{cr}, \mathrm{p}}=k \frac{\pi^{2} E}{12\left(1-v^{2}\right)}\left(\frac{t}{b}\right)^{2}
$$

Considering the typical dimensions of structural members, plate elements within cross-sections are generally sufficiently long that the influence of the plate aspect ratio is negligible. The restraint conditions along the longitudinal plate edges are generally idealized as simplysupported or fixed. In most practical applications, the boundary conditions along the longitudinal edges of individual cross-section plates lie between these idealised limits and can be represented by an elastic rotational spring [26]. In general, as the level of restraint along the longitudinal plate edges increases (i.e. approaching fixed boundary conditions) the buckling coefficient $k$, and thus the local buckling stress, increases $[12,13]$, while the local buckling halfwavelength reduces [27].

The applied stress distribution across the loaded edges of the plates within a cross-section typically varies from pure compression to pure bending. Uniform compression is the most severe loading condition and thus results in the lowest elastic local buckling stress. As the applied stress distribution becomes increasingly non-uniform, the local buckling stress of the plate increases. The parameter $\psi$, defined in Eq. (2), is typically used to represent linearly varying applied stress distributions across the loaded edge of a plate, where $\sigma_{1}$ and $\sigma_{2}$ are the maximum and minimum stress applied to the plate respectively, with compressive stresses taken as positive. A value of $\psi=1$ corresponds to pure compression, while $\psi=-1$ corresponds to pure bending.

$$
\psi=\frac{\sigma_{2}}{\sigma_{1}}
$$


Explicit expressions for the plate buckling coefficient $k$ as a function of the applied stress distribution $\psi$ are provided in EN 1993-1-5 [28] for internal and outstand plates with simplysupported boundary conditions along the adjoined edges, as summarized in Table 1. These expressions are applicable to plates subjected to stress distributions where $-3 \leq \psi \leq 1$; this range was found to be sufficient to cover the web plates of all the three-flanged cross-sections subjected to major axis bending (or major axis bending plus compression) considered in this study. Note that the stress distribution across the outstand flanges is always uniform (i.e. $\psi_{\mathrm{f}}=$ 1) for any combination of major axis bending and compression.

For plates with fixed boundary conditions along the adjoined edges, Gardner et al. [1] developed equivalent expressions to those presented in EN 1993-1-5, as set out in Table 2. The expressions were calibrated against the results of finite strip analysis [3], but were limited to stress distributions in which $-1 \leq \psi \leq 1$. While this is adequate for single I-sections, in threeflanged cross-sections, lower $\psi$ values often arise in the web. Hence, using the same method as employed in [1], an additional expression for the plate buckling coefficient $k$ for internal elements with fixed boundary conditions has been derived herein for $-3 \leq \psi \leq-1$, as shown in Fig. 2 and included in Table 2.

\subsection{Elastic local buckling of I-sections}

\subsubsection{Introduction}

When isolated plates are combined to form structural cross-sections, the interaction between the plate elements generally results in the elastic local buckling stress of the full cross-section exceeding that of the most slender constituent plate element with simply-supported boundary conditions along the adjoined edges. There are two primary causes of element interaction in structural cross-sections: (1) differences in elastic buckling stresses between isolated plates and (2) incompatibility in local buckling half-wavelengths between isolated plates. In the former case, the non-critical plates (i.e. the isolated plates with the higher elastic local buckling stresses) 
are able to provide rotational restraint to the edges of the critical plate (i.e. the isolated plate with the lowest elastic local buckling stress). In the latter case, the interconnectivity between the plates prevents them from buckling into their natural isolated buckling mode shapes, hence resulting in an enhanced elastic buckling stress; this effect is particularly pronounced in crosssections composed of both internal and outstand elements (e.g. I-sections), which can have very different local buckling half-wavelengths when considered in isolation.

\subsubsection{Existing formulae}

Gardner et al. [1] developed expressions to calculate the elastic local buckling stress of full cross-sections, allowing for the effects of element interaction. The underlying concept is that the elastic local buckling stress of a full cross-section $\sigma_{\mathrm{cr}, \mathrm{cs}}$ is bound by the elastic local buckling stresses of the isolated critical plates with simply-supported $\sigma_{\mathrm{cr}, \mathrm{p}}^{\mathrm{SS}}$ and fixed $\sigma_{\mathrm{cr}, \mathrm{p}}^{\mathrm{F}}$ boundary conditions along the adjoined edges, as given by Eq. (3).

$$
\sigma_{\mathrm{cr}, \mathrm{cs}}=\sigma_{\mathrm{cr}, \mathrm{p}}^{\mathrm{SS}}+\zeta\left(\sigma_{\mathrm{cr}, \mathrm{p}}^{\mathrm{F}}-\sigma_{\mathrm{cr}, \mathrm{p}}^{\mathrm{SS}}\right)
$$

The lower bound elastic local buckling stress $\sigma_{\text {cr,p }}^{\text {ss }}$ is taken as the minimum elastic local buckling stress of the constituent flange or web plate elements forming the cross-section, assuming simply-supported boundary conditions along the adjoined edges, denoted $\sigma_{\mathrm{cr}, \mathrm{f}}^{\mathrm{SS}}$ and $\sigma_{\mathrm{cr}, \mathrm{w}}^{\mathrm{SS}}$ respectively, as given in Eq. (4). Similarly, the upper bound stress $\sigma_{\mathrm{cr}, \mathrm{p}}^{\mathrm{F}}$ is equal to the minimum of the elastic local buckling stresses of the flange $\sigma_{\mathrm{cr}, \mathrm{f}}^{\mathrm{F}}$ and the web $\sigma_{\mathrm{cr}, \mathrm{w}}^{\mathrm{F}}$ with fixed boundary conditions along the adjoined longitudinal edges, as given in Eq. (5). Note that the calculation of the local buckling stresses of the individual plates is based on the centreline geometry of the cross-section, as indicated in Fig. 3 for a single I-section, where the adopted notation is also illustrated.

$$
\sigma_{\mathrm{cr}, \mathrm{p}}^{\mathrm{SS}}=\min \left(\sigma_{\mathrm{cr}, \mathrm{f}}^{\mathrm{SS}}, \sigma_{\mathrm{cr}, \mathrm{w}}^{\mathrm{SS}}\right)
$$




$$
\sigma_{\mathrm{cr}, \mathrm{p}}^{\mathrm{F}}=\min \left(\sigma_{\mathrm{cr}, \mathrm{f}}^{\mathrm{F}}, \sigma_{\mathrm{cr}, \mathrm{w}}^{\mathrm{F}}\right)
$$

The degree of element interaction is defined through the interaction coefficient $\zeta$, which ranges from 0 (i.e. no element interaction, corresponding to the simply-supported lower bound) and 1 (i.e. full element interaction, corresponding to the upper bound of fixed boundary conditions along the adjoined edges of the critical plate). Gardner et al. [1] back-calculated the level of element interaction within a cross-section by rearranging Eq. (3) into Eq. (6), and hence developed predictive expressions for $\zeta$ for different cross-section profiles and loading conditions.

$$
\zeta=\frac{\sigma_{\mathrm{cr}, \mathrm{cs}}-\sigma_{\mathrm{cr}, \mathrm{p}}^{\mathrm{sS}}}{\sigma_{\mathrm{cr}, \mathrm{p}}^{\mathrm{F}}-\sigma_{\mathrm{cr}, \mathrm{p}}^{\mathrm{sS}}}, \text { but } 0 \leq \zeta \leq 1
$$

For the case of single I-sections subjected to combined compression and major axis bending, the interaction coefficient $\zeta$ is given by Eq. (7) and (8) for flange and web critical cases (defined through the parameter $\phi$ below) respectively.

$$
\begin{aligned}
& \text { For } \phi<1 \text { (i.e. flange critical), } \zeta=0.15 \frac{t_{\mathrm{f}}}{t_{\mathrm{w}}} \phi \geq \frac{t_{\mathrm{w}}}{t_{\mathrm{f}}}(0.4-0.25 \phi), \text { but } 0 \leq \zeta \leq 1 \\
& \text { For } \phi \geq 1 \text { (i.e. web critical), } \zeta=\frac{t_{\mathrm{f}}}{t_{\mathrm{w}}}\left(0.45-\frac{0.3}{\phi^{2}}\right) \text {, but } 0 \leq \zeta \leq 1
\end{aligned}
$$

The parameter $\phi$, defined by Eq. (9), is the ratio of the elastic local buckling stress of the isolated and simply-supported flange to that of the web, and is used to determine whether the flange or the web is critical. Values of $\phi$ less than unity correspond to flange critical cases, suggesting that the web is able to provide rotational restraint to the flange. Conversely, values of $\phi$ greater than unity suggest that the web plate is critical and that the flange can provide rotational restraint to the web. When $\phi$ has a value close to unity, the isolated and simplysupported flange and web plates have similar elastic local buckling stresses and the degree of 
element interaction is typically low. Conversely, as $\phi$ approaches zero (flange critical) or very large values (web critical), the level of element interaction increases.

$$
\phi=\frac{\sigma_{\mathrm{cr}, \mathrm{f}}^{\mathrm{SS}}}{\sigma_{\mathrm{cr}, \mathrm{w}}^{\mathrm{sS}}}
$$

This means of calculating the elastic local buckling stress of I-sections is straightforward and explicit, and has already been successfully applied within a recently developed method of design by advanced inelastic analysis with strain limits $[25,29,30]$.

\subsubsection{Extension of existing formulae to a broader range of stress distribution ratios}

The existing formulae given in Section 2.2.2 for calculating the elastic local buckling stress of I-sections [1] were developed for single I-sections under combined compression and major axis bending, in which the stress distribution ratio in the web $\psi_{\mathrm{w}}$ always lies between -1 and 1 . However, in three-flanged cross-sections, the stress distribution in the web can be such that $\psi_{\mathrm{w}}$ $<-1$. Hence, it is necessary to evaluate the applicability of the existing formulae in this range of stress distributions. The elastic local buckling stresses calculated using Eq. (3) for 100 different I-sections subjected to web stress distribution ratios in the range of $-2 \leq \psi_{\mathrm{w}}<-1$ were compared against results obtained from finite strip analysis (FSA) performed using the software CUFSM v4.05 [3]. In the analyses, the cross-sections were modelled based on centreline dimensions and each flange and web was discretized into 8 strips across the plate width. The following material properties were used throughout the paper: Young's modulus $E$ $=210000 \mathrm{MPa}$ and Poisson's ratio $v=0.3$. The mean value of the ratios of the elastic local

buckling stresses obtained from Eq. (3) to those obtained from FSA, i.e. $\sigma_{\mathrm{cr}, \mathrm{cs}}^{\mathrm{Eq}} / \sigma_{\mathrm{cr}, \mathrm{cs}}^{\mathrm{FA}}$, was found to be equal to 1.013 , with a coefficient of variation $(\mathrm{CoV}) 0.035$; the maximum and minimum values of $\sigma_{\mathrm{cr}, \mathrm{CS}}^{\mathrm{Eq}} / \sigma_{\mathrm{cr}, \mathrm{cs}}^{\mathrm{FS}}$ were 1.080 and 0.927 respectively. Thus, it is concluded that the range of applicability of the formulae presented in [1] for calculating the elastic local buckling stress of I-sections can be extended to stress distribution ratios where $-2 \leq \psi_{\mathrm{w}} \leq 1$. 


\subsubsection{Extension of existing formulae to shallow I-sections}

The formulae presented in [1] were established based on standard I-sections listed in European and American catalogues, leading to a normalized dimensional range of applicability of $0.89 \leq$ $\left(h / t_{\mathrm{w}}\right)\left(t_{\mathrm{f}} / b\right) \leq 6.36$. However, I-sections of shallower proportions can exist in longitudinallystiffened and haunched beams, and the accuracy and suitability of the expressions developed in [1] need to be assessed for shallower I-sections in which $\left(h / t_{\mathrm{w}}\right)\left(t_{\mathrm{f}} / b\right)<0.89$. Comparisons of the predictions of elastic local buckling stresses obtained from Eq. (3) are therefore made against those obtained from finite strip analysis performed using CUFSM. During the finite strip analysis of some of the shallower I-sections, global buckling had to be inhibited by the application of suitable boundary conditions at the web-to-flange junction (see Fig. 4) to enable the development of local buckling. In some cases, the signature curve obtained using CUFSM displayed no distinct local buckling minimum, as shown in Fig. 4. This issue can be solved by using the approach "FSM@cFSM-L constrained finite strip method (i.e. cFSM) is first employed to determine the half-wavelength $L_{\mathrm{cr}}$ corresponding to the pure local buckling mode; the critical load factor is then taken as that obtained from an unconstrained finite strip analysis at the same half-wavelength $L_{\mathrm{cr}}$. Note that this approach provides critical load factor predictions close to those predicted by the point of inflection on the signature curve [1]. Comparisons between the predicted values of elastic buckling stress $\sigma_{\mathrm{cr}, \mathrm{cs}}^{\mathrm{Eq}}$ determined from Eq. (3) and the numerical values $\sigma_{\mathrm{cr}, \mathrm{cs}}^{\mathrm{FA}}$ determined using CUFSM for a series of shallow I-sections under different loading conditions ranging from pure compression to pure major axis bending are shown in Fig. 5 (a). It can be seen that elastic buckling stresses calculated using Eq. (3) $\sigma_{\mathrm{cr}, \mathrm{cs}}^{\mathrm{Eq}}$ become increasingly conservative relative to the numerical results as the value of $\left(h / t_{\mathrm{w}}\right)\left(t_{\mathrm{f}} / b\right)$ reduces. This conservatism is overcome by adjusting the interaction coefficient $\zeta$ in the range $\left(h / t_{\mathrm{w}}\right)\left(t_{\mathrm{f}} / b\right)<0.89$. The difference between the back-calculated interaction coefficients obtained from CUFSM $\zeta^{\text {FSA }}$ and the values 
calculated from Eqs. (7) and (8) $\zeta^{\mathrm{Eq}}$ is shown in Fig. 5 (b). This difference can be predicted using the fitted parabola $\zeta^{\mathrm{FSA}}-\zeta^{\mathrm{Eq}}=0.4\left[0.89-\left(h / t_{\mathrm{w}}\right)\left(t_{\mathrm{f}} / b\right)\right]^{2}$, which can be used to modify the existing expression. The flange typically becomes the critical plate element in shallow Isections; hence, to calculate $\zeta$ in the range $\phi<1$, Eq. (7), which remains applicable in the range $0.89 \leq\left(h / t_{\mathrm{w}}\right)\left(t_{\mathrm{f}} / b\right) \leq 6.36$, can be supplemented with Eq. (10). As shown in Fig. 5 (a), the accuracy of predictions is markedly improved using the modified equations.

$$
\begin{aligned}
& \text { For } \phi<1 \text { and } 0.89 \leq \frac{h}{t_{\mathrm{w}}} \frac{t_{\mathrm{f}}}{b} \leq 6.36, \\
& \qquad \begin{aligned}
\zeta & =0.15 \frac{t_{\mathrm{f}}}{t_{\mathrm{w}}} \phi \geq \frac{t_{\mathrm{w}}}{t_{\mathrm{f}}}(0.4-0.25 \phi), \text { but } 0 \leq \zeta \leq 1
\end{aligned}
\end{aligned}
$$

For $\phi<1$ and $\frac{h}{t_{\mathrm{w}}} \frac{t_{\mathrm{f}}}{b}<0.89$,

$$
\zeta=\max \left(0.15 \frac{t_{\mathrm{f}}}{t_{\mathrm{w}}} \phi, \frac{t_{\mathrm{w}}}{t_{\mathrm{f}}}(0.4-0.25 \phi)\right)+0.4\left(0.89-\frac{h}{t_{\mathrm{w}}} \frac{t_{\mathrm{f}}}{b}\right)^{2} \text {, but } 0 \leq \zeta \leq 1
$$

\section{Elastic local buckling behaviour of three-flanged cross-sections}

\subsection{Loading cases and concept}

Three-flanged cross-sections can experience either sagging or hogging bending moments e.g. in the span or support regions for continuous, longitudinally-stiffened plate girders (see Fig. 6(a)) and in the haunch or apex regions of portal frames subjected to gravity loading (see Fig. 6(b)) or wind uplift (see Fig. 6(c)). Accordingly, the stress distribution in three-flanged crosssections can be categorised into one of two states: (i) Case 1, corresponding to the maximum axial compression occurring within the deeper I-section and (ii) Case 2, corresponding to the maximum axial compression occurring within the shallower I-section. These two states are illustrated in Fig. 6.

Considering these two cases, a similar approach to that developed by Gardner et al. [1] for calculating the elastic local buckling stress of single I-sections is employed herein for three- 
flanged cross-sections. First, the three-flanged cross-section is considered as two single Isections, i.e. the deeper I-section and the shallower I-section, that share a common middle flange; the compound section is then classified as either deeper section critical or shallower section critical, depending on which has the lower critical local buckling load factor. The above scenarios are summarised in Table 3.

Similar to the interaction between the flange and web plates within single I-sections, in the case of three-flanged cross-sections, the deeper I-section and the shallower I-section also interact with each other. This is because the non-critical part of the three-flanged cross-section (i.e. either the deeper or the shallower section) is able to provide rotational restraint to the critical part. In the proposed approach, the interaction between the plates within the deeper and shallower I-sections are captured through the interaction coefficients, $\zeta_{\mathrm{d}}$ and $\zeta_{\mathrm{s}}$ respectively, determined from Eq. (7) or (8). The combined interaction, both within and between the two cross-section parts (i.e. the deeper I-section and the shallower I-section), are then determined from the compound interaction coefficient $\zeta_{\mathrm{d}+\mathrm{s}}$. For deeper section critical scenarios, $\zeta_{\mathrm{d}+\mathrm{s}}$ is calculated from Eq. (11), where $\zeta_{\mathrm{s}}^{*}$ represents the influence of the shallower section on the deeper section; for shallower section critical scenarios, $\zeta_{\mathrm{d}+\mathrm{s}}$ is calculated from Eq. (12), where $\zeta_{\mathrm{d}}^{*}$ represents the influence of the deeper section on the shallower section. Note that in both deeper section and shallower section critical scenarios, the compound interaction coefficient for the three-flanged cross-section $\zeta_{\mathrm{d}+\mathrm{s}}$ maintains a value between 0 and 1.

$$
\begin{aligned}
& \text { For deeper section critical scenarios, } \zeta_{\mathrm{d}+\mathrm{s}}=\zeta_{\mathrm{d}}+\zeta_{\mathrm{s}}^{*} \text {, but } 0 \leq \zeta_{\mathrm{d}+\mathrm{s}} \leq 1 \\
& \text { For shallower section critical scenarios, } \zeta_{\mathrm{d}+\mathrm{s}}=\zeta_{\mathrm{s}}+\zeta_{\mathrm{d}}^{*} \text {, but } 0 \leq \zeta_{\mathrm{d}+\mathrm{s}} \leq 1
\end{aligned}
$$

\subsection{Finite strip analysis}

Values of the aforementioned compound interaction coefficients $\zeta_{\mathrm{d}+\mathrm{s}}$ were back-calculated from the results of finite strip analyses performed on three-flanged cross-sections; the analyses 
were carried out using the software CUFSM v4.05 [3]. Corresponding single deeper and shallower sections were also analysed under the same stress conditions as in the three-flanged cross-section to aid the assessment of the results. For straightforward interpretation of the results, the maximum compressive stress applied to the three-flanged cross-sections was taken equal to unity, such that the obtained values of the critical load factor were equal to the elastic local buckling stress.

For each of Cases 1 and 2, 4500 three-flanged cross-sections consisting of 100 different deeper sections and 5 different shallower sections under 9 different applied stress distributions were analysed. The considered deeper cross-sections included standard hot-finished European (IPE, HEA, HEB, UKC, UKB) and American (W, S, HP) I-sections. In all cases, the same section size was used for the deeper and shallower I-sections, and a series of different ratios of shallower section height to deeper section height $h_{\mathrm{s}} / h_{\mathrm{d}}$ were considered: doubly symmetric three-flanged cross-sections $\left(h_{\mathrm{s}}+t_{\mathrm{f}}=h_{\mathrm{d}}\right)$, and $h_{\mathrm{s}} / h_{\mathrm{d}}=0.9,0.7,0.4,0.1$. Nine stress distributions ranging from pure compression to pure major axis bending were considered. The superscript and subscript notation adopted herein to distinguish between the various critical stresses is shown in Fig. 7, where compressive stresses are taken as positive.

\subsubsection{Case 1 - maximum compression in deeper I-section}

For Case 1, the overall linearly varying stress distribution applied over the depth of the threeflanged cross-section is described through the parameter $\psi_{\mathrm{dw}+\mathrm{sw}}$, which is equal to the ratio of the stress at the outer flange of the shallower section to that at the outer flange of the deeper section, i.e. $\sigma_{2, \mathrm{sw}} / \sigma_{1, \mathrm{dw}}$. The stress distributions, local buckling shapes and critical local buckling load factors of (a) a three-flanged cross-section and (b) the corresponding single deeper Isection and single shallower I-section are shown in Fig. 8. In Case 1, the critical load factor of the deeper section is always the same or lower than that of the shallower section, i.e. $\alpha_{\mathrm{cr}, \mathrm{d}} \leq$ $\alpha_{\mathrm{cr}, \mathrm{s}}$. The shallower section can therefore provide restraint to the deeper section. The influence 
of the shallower section on the deeper section can be seen through the difference between the critical load factor of the three-flanged cross-section $\alpha_{\mathrm{cr}, \mathrm{d}+\mathrm{s}}$ and that of the corresponding single deeper I-section $\alpha_{\mathrm{cr}, \mathrm{d}}$. This is shown in Fig. 9, for a series of three-flanged cross-sections with different $h_{\mathrm{s}} / h_{\mathrm{d}}$ ratios under a range of loading conditions. It can be seen from the figure that, for this case, the influence of the shallower section on the deeper section is small, with a the maximum improvement in critical load factor of $10 \%$; this is because the maximum compressive stress and thus the critical region of the three-flanged cross-section is located towards the outer flange of the deeper section, while the rotational restraint from the shallower section is provided to the middle flange; for the same reason, the highest $\alpha_{\mathrm{cr}, \mathrm{d}+\mathrm{s}} / \alpha_{\mathrm{cr}, \mathrm{d}}$ ratios (i.e. the scenarios in which the shallower section has the greatest influence) arise in the more compression dominated load cases where $\psi_{\mathrm{dw}+\mathrm{sw}}$ approaches unity. Note that for some doubly symmetric three-flanged cross-sections under pure compression, the deeper and shallower sections buckle simultaneously, and with the common middle flange, the compound threeflanged cross-section buckles at a lower stress than each single I-section.

\subsubsection{Case 2 - maximum compression in shallower I-section}

For Case 2, where the maximum compressive stress arises in the haunch, the parameter $\psi_{\mathrm{dw}+\mathrm{sw}}$ $=\sigma_{2, \mathrm{dw}} / \sigma_{1, \mathrm{sw}}$ is used to describe the linearly varying stress distribution applied over the depth of the three-flanged cross-section, as shown in Figs. 10 and 11. Fig. 10 shows an example of a shallower section critical situation, where $\alpha_{\mathrm{cr}, \mathrm{s}}<\alpha_{\mathrm{cr}, \mathrm{d}}$, while in Fig. 11, the deeper section is critical, i.e. $\alpha_{\mathrm{cr}, \mathrm{d}} \leq \alpha_{\mathrm{cr}, \mathrm{s}}$.

For shallower section critical scenarios in Case 2, the influence of the deeper section on the critical shallower section is small, with a maximum improvement in critical load factor of less than 6\%, as shown in Fig. 12, where the difference between the critical load factor of a series of the three-flanged cross-sections $\alpha_{\mathrm{cr}, \mathrm{d}+\mathrm{s}}$ and their corresponding critical single shallower Isections $\alpha_{\mathrm{cr}, \mathrm{s}}$ are presented. This is because the maximum compressive stress and thus the 
critical region of the three-flanged cross-section is located towards the outer flange of the shallower section, while the rotational restraint from the deeper section is provided to the middle flange.

In contrast, for deeper section critical scenarios in Case 2, the shallower section can offer significant restraint to the deeper section, resulting in improvements in critical load factors of up to about 40\%, as shown in Fig. 13, where the difference between the critical load factor of a series of the three-flanged cross-sections $\alpha_{\mathrm{cr}, \mathrm{d}+\mathrm{s}}$ and their corresponding critical single deeper I-sections $\alpha_{\mathrm{cr}, \mathrm{d}}$ are presented. This is because the maximum compressive stress and thus the critical region of the three-flanged cross-section is located towards the middle flange, and the rotational restraint from the adjoined shallower section is also provided to this region.

It can be seen from Figs. 12 and 13 that, as in Case 1, there are also some scenarios in Case 2 where the compound three-flanged cross-section buckles at a lower stress than the critical single I-section; all these scenarios arise where $\alpha_{\mathrm{cr}, \mathrm{d}} \approx \alpha_{\mathrm{cr}, \mathrm{s}}$, as explained in Section 3.2.1.

\subsection{Influence of shallower section in deeper section critical scenarios in Case 2}

The results presented in Fig. 13 show that the shallower section can offer significant restraint to the deeper section in deeper section critical scenarios in Case 2. The is explored further in this sub-section. First, the deeper section critical scenarios in Case 2 are further categorised into either deeper section web critical or deeper section flange critical, depending on which isolated plate within the deeper section has the lower elastic local buckling stress (assuming simply-supported boundary conditions along the adjoined edges): $\alpha_{\mathrm{cr}, \mathrm{d}} \leq \alpha_{\mathrm{cr}, \mathrm{s}}$ and $\phi_{\mathrm{d}}=\sigma_{\mathrm{cr}, \mathrm{df}}^{\mathrm{ss}} / \sigma_{\mathrm{cr}, \mathrm{dw}}^{\mathrm{ss}} \geq 1$ implies that the deeper section web is critical, while $\alpha_{\mathrm{cr}, \mathrm{d}} \leq \alpha_{\mathrm{cr}, \mathrm{s}}$ and $\phi_{\mathrm{d}}<$ 1 indicates that the deeper section flange is critical. Note that the latter classification does not mean the deeper section flange is the critical plate element within the compound three-flanged 
cross-section; this 'artificial' case is only considered as part of the analysis and calculation process.

The restraining influence of the shallower section on the deeper section can be assessed by inspecting the buckling coefficient $k$ of its critical plate element. This is illustrated in Fig. 14, where several pairs of back-calculated buckling coefficients for the web within the single deeper I-section $k_{\mathrm{dw}}$ (using Eq. (13)) and the web within the three-flanged cross-section $k_{\mathrm{dw}+\mathrm{sw}}$ (using Eq. (14)) are plotted for deeper section web critical cases. Both the $k_{\mathrm{dw}}$ and $k_{\mathrm{dw}+\mathrm{sw}}$ values lie between the lower bound value of the buckling coefficient for isolated plates with simplysupported boundary conditions along the adjoined edges and the upper bound value for isolated plates with fixed boundary conditions along the adjoined edges, as obtained from Tables 1 and 2. However, the $k_{\mathrm{dw}+\mathrm{sw}}$ values are consistently higher than the $k_{\mathrm{dw}}$ values, and closer to the upper bound; this illustrates that the rotational restraint afforded to the deeper section by the shallower section, enhances the buckling coefficient of the critical plate element towards the upper bound value for fixed boundary conditions.

$$
\begin{gathered}
k_{\mathrm{dw}}=\sigma_{\mathrm{cr}, \mathrm{d}} /\left[\frac{\pi^{2} E}{12\left(1-v^{2}\right)}\left(\frac{\mathrm{t}_{\mathrm{w}}}{h_{\mathrm{d}}-t_{\mathrm{f}}}\right)^{2}\right] \\
k_{\mathrm{dw}+\mathrm{sw}}=\sigma_{\mathrm{cr}, \mathrm{d}+\mathrm{s}} \psi_{\mathrm{sw}} /\left[\frac{\pi^{2} E}{12\left(1-v^{2}\right)}\left(\frac{\mathrm{t}_{\mathrm{w}}}{h_{\mathrm{d}}-t_{\mathrm{f}}}\right)^{2}\right]
\end{gathered}
$$

The enhancement in the elastic buckling stresses of the deeper section due to the rotational restraint from the shallower section in a series of three-flanged cross-sections is assessed in Fig. 15 , where the ratio $\alpha_{\mathrm{cr}, \mathrm{d}+\mathrm{s}} / \alpha_{\mathrm{cr}, \mathrm{d}}$ is presented in relation to the parameter $\phi_{\mathrm{d}}=\sigma_{\mathrm{cr}, \mathrm{df}}^{\mathrm{ss}} / \sigma_{\mathrm{cr}, \mathrm{dw}}^{\mathrm{ss}}$. It can be seen that in three-flanged cross-sections with very large $\phi_{\mathrm{d}}$ values (deeper section web critical) or where $\phi_{\mathrm{d}}$ approaches zero (deeper section flange critical), the beneficial effect of the shallower section is small (i.e. $\alpha_{\mathrm{cr}, \mathrm{d}+\mathrm{s}} \approx \alpha_{\mathrm{cr}, \mathrm{d}}$ ); this is because in the corresponding single 
deeper I-sections, the web (for high $\phi_{\mathrm{d}}$ values) or flange (for low $\phi_{\mathrm{d}}$ values) are already close to fixed boundary conditions along their adjoined edges (i.e. at the web-to-flange junction) and thus there is little or no scope for further increases to their elastic local buckling stresses. Conversely, in three-flanged cross-sections with $\phi_{\mathrm{d}}$ values close to unity, the beneficial effect of the shallower section is significant, with increases in elastic buckling stresses of up to about $40 \%$; this is because in the corresponding single deeper I-sections, the web and flange have approximately equal elastic local buckling stresses, hence the boundary conditions at the webflange junction are close to simply-supported and the rotational restraint provided by the adjoined shallower section is highly beneficial.

\subsection{Determination of $\zeta_{\mathrm{s}}^{*}$ for deeper section critical scenarios in Case 2}

In order to capture quantitively the influence of the shallower section on the deeper section in deeper section critical scenarios in Case 2, the interaction coefficient $\zeta_{\mathrm{s}}^{*}$ is introduced; this is used to represent the difference between the interaction coefficient to evaluate flange-web interaction within the single deeper I-section $\zeta_{\mathrm{d}}$ and that for the compound three-flanged crosssection $\zeta_{\mathrm{d}+\mathrm{s}}$, as expressed by Eq. (15).

$$
\zeta_{\mathrm{s}}^{*}=\zeta_{\mathrm{d}+\mathrm{s}}-\zeta_{\mathrm{d}}
$$

The interaction coefficients $\zeta_{\mathrm{d}}$ and $\zeta_{\mathrm{d}+\mathrm{s}}$ can be back-calculated using Eqs. (16) and (17), according to the elastic buckling stresses of the single deeper I-section $\sigma_{\mathrm{cr}, \mathrm{d}}$ and three-flanged cross-section $\sigma_{\mathrm{cr}, \mathrm{d}+\mathrm{s}}$, as obtained from finite strip analysis.

$$
\begin{gathered}
\zeta_{\mathrm{d}}=\frac{\sigma_{\mathrm{cr}, \mathrm{d}}-\sigma_{\mathrm{cr}, \mathrm{dp}}^{\mathrm{SS}}}{\sigma_{\mathrm{cr}, \mathrm{dp}}^{\mathrm{F}}-\sigma_{\mathrm{cr}, \mathrm{dp}}^{\mathrm{SS}}}, \text { but } 0 \leq \zeta_{\mathrm{d}} \leq 1 \\
\zeta_{\mathrm{d}+\mathrm{s}}=\frac{\sigma_{\mathrm{cr}, \mathrm{d}+\mathrm{s}} \psi_{\mathrm{sw}}-\sigma_{\mathrm{cr}, \mathrm{dp}}^{\mathrm{SS}}}{\sigma_{\mathrm{cr}, \mathrm{dp}}^{\mathrm{F}}-\sigma_{\mathrm{cr}, \mathrm{dp}}^{\mathrm{SS}}}, \text { but } 0 \leq \zeta_{\mathrm{d}+\mathrm{s}} \leq 1
\end{gathered}
$$


As shown in Fig. 16 (a) and (b) for deeper section flange critical and deeper section web critical scenarios respectively, both $\zeta_{\mathrm{d}}$ and $\zeta_{\mathrm{d}+\mathrm{s}}$ lie between 0 and 1, i.e. as discussed above, although the shallower section clearly provides benefit through rotational restraint to the deeper section (indicated by the $\zeta_{\mathrm{d}+\mathrm{s}}$ values being greater than the corresponding $\zeta_{\mathrm{d}}$ values), the maximum value of the elastic buckling stress of the three-flanged cross-section is limited to that of the critical individual plate element with fixed boundary conditions along the adjoined edges. As shown in Fig. 17, the difference between these two coefficients, i.e. $\zeta_{\mathrm{s}}^{*}$, exhibits a consistent trend, i.e. lower $\zeta_{\mathrm{s}}^{*}$ values arise in the three-flanged cross-sections with very high or low (approaching 0) $\phi_{\mathrm{d}}$ values, while higher $\zeta_{\mathrm{s}}^{*}$ values appear in the three-flanged cross-sections with $\phi_{\mathrm{d}}$ values close to unity.

Fig. 18 shows the back-calculated normalised $\zeta_{\mathrm{s}}^{*}$ values for all deeper section critical results in Case 2. According to the trend of the results, predictive equations to determine $\zeta_{\mathrm{s}}^{*}$ are proposed for both the deeper section flange critical $\left(\phi_{\mathrm{d}}<1\right)$ and deeper section web critical ( $\phi_{\mathrm{d}}$ $\geq 1$ ) scenarios, as expressed by Eq. (18). The formulae, which are plotted in Fig. 18, are dependent on the ratio of the elastic buckling stress of the shallower section to that of the deeper section $\gamma=\alpha_{\mathrm{cr}, \mathrm{s}} / \alpha_{\mathrm{cr}, \mathrm{d}}$, the stress distribution in the shallower section web $\psi_{\mathrm{sw}}$ and the ratio of flange to web thickness $t_{\mathrm{f}} / t_{\mathrm{w}}$, and ensure continuity of predictions between Case 1 and Case 2 and across the full range of loading scenarios.

$$
\zeta_{\mathrm{s}}^{*}= \begin{cases}3.7 \frac{t_{\mathrm{f}}}{t_{\mathrm{w}}}\left(1-\psi_{\mathrm{sw}}^{2}\right)\left(1-\frac{1}{\gamma}\right) \phi_{\mathrm{d}}^{2} & \text { for } \phi_{\mathrm{d}}<1 \\ 3.7 \frac{t_{\mathrm{f}}}{t_{\mathrm{w}}}\left(1-\psi_{\mathrm{sw}}^{2}\right)\left(1-\frac{1}{\gamma}\right) / \phi_{\mathrm{d}}^{2} & \text { for } \phi_{\mathrm{d}} \geq 1\end{cases}
$$




\section{Development of formulae for predicting elastic local buckling stress of three-}

\section{flanged cross-sections}

\subsection{Development of predictive expressions}

Based on the behaviour described above, formulae for predicting the elastic local buckling stress of three-flanged cross-sections are developed herein. The overall framework of the predictive expressions is illustrated in Fig. 19. First, the case in question (i.e. Case 1 or Case 2) is identified.

For Case 1 (maximum compression in deeper I-section), the outer portion of the deeper section is always the critical part of the three-flanged cross-section, and the influence of the shallower section is small. Thus, it is assumed that $\zeta_{\mathrm{d}+\mathrm{s}}=\zeta_{\mathrm{d}}\left(\right.$ i.e. $\left.\zeta_{\mathrm{s}}^{*}=0\right)$, and the elastic local buckling stress of the three-flanged cross-section is given by:

$$
\sigma_{\mathrm{cr}, \mathrm{d}+\mathrm{s}}=\sigma_{\mathrm{cr}, \mathrm{d}}=\sigma_{\mathrm{cr}, \mathrm{dp}}^{\mathrm{SS}}+\zeta_{\mathrm{d}}\left(\sigma_{\mathrm{cr}, \mathrm{dp}}^{\mathrm{F}}-\sigma_{\mathrm{cr}, \mathrm{dp}}^{\mathrm{SS}}\right)
$$

For Case 2 (maximum compression in shallower I-section), first, Eq. (3) is used to calculate elastic local buckling critical stresses of the single deeper I-section $\sigma_{\mathrm{cr}, \mathrm{d}}$ and the single shallower I-section $\sigma_{\mathrm{cr}, \mathrm{s}}$; then the critical load factors of these two sections are calculated: $\alpha_{\mathrm{cr}, \mathrm{d}}=\sigma_{\mathrm{cr}, \mathrm{d}} / \psi_{\mathrm{sw}}$ and $\alpha_{\mathrm{cr}, \mathrm{s}}=\sigma_{\mathrm{cr}, \mathrm{s}}$, identifying whether the shallower $\left(\gamma=\alpha_{\mathrm{cr}, \mathrm{s}} / \alpha_{\mathrm{cr}, \mathrm{d}}<1\right)$ or the deeper $\left(\gamma=\alpha_{\mathrm{cr}, \mathrm{s}} / \alpha_{\mathrm{cr}, \mathrm{d}}\right.$ $\geq 1)$ section is critical.

For the shallower section critical scenarios, the influence of the deeper section is small; hence it is assumed that $\zeta_{\mathrm{d}}^{*}=0$, thus $\zeta_{\mathrm{d}+\mathrm{s}}=\zeta_{\mathrm{s}}$, and the elastic local buckling stress of the three-flanged cross-section is given by:

$$
\sigma_{\mathrm{cr}, \mathrm{d}+\mathrm{s}}=\sigma_{\mathrm{cr}, \mathrm{s}}=\sigma_{\mathrm{cr}, \mathrm{sp}}^{\mathrm{SS}}+\zeta_{\mathrm{s}}\left(\sigma_{\mathrm{cr}, \mathrm{sp}}^{\mathrm{F}}-\sigma_{\mathrm{cr}, \mathrm{sp}}^{\mathrm{SS}}\right)
$$

For the deeper section critical scenarios, first the critical plate within the deeper cross-section (i.e. either the deeper section flange or web) is identified according to the value of $\phi_{\mathrm{d}}$ 
calculated from Eq. (9); the influence of the shallower section on the deeper section is then determined through $\zeta_{\mathrm{s}}^{*}$ using Eq. (18). Finally, the compound interaction coefficient $\zeta_{\mathrm{d}+\mathrm{s}}$ and the elastic local buckling stress $\sigma_{\mathrm{cr}, \mathrm{d}+\mathrm{s}}$ of the three-flanged cross-section are given by:

$$
\begin{gathered}
\zeta_{\mathrm{d}+\mathrm{s}}=\zeta_{\mathrm{d}}+\zeta_{\mathrm{s}}^{*} \text {, but } 0 \leq \zeta_{\mathrm{d}+\mathrm{s}} \leq 1 \\
\sigma_{\mathrm{cr}, \mathrm{d}+\mathrm{s}}=\left[\sigma_{\mathrm{cr}, \mathrm{dp}}^{\mathrm{sS}}+\zeta_{\mathrm{d}+\mathrm{s}}\left(\sigma_{\mathrm{cr}, \mathrm{dp}}^{\mathrm{F}}-\sigma_{\mathrm{cr}, \mathrm{dp}}^{\mathrm{sS}}\right)\right] / \psi_{\mathrm{sw}}
\end{gathered}
$$

\subsection{Evaluation of developed proposal}

In this section, the accuracy of the predictions of the elastic local buckling stresses of threeflanged cross-sections using the formulae developed herein is evaluated against results obtained using CUFSM; the predictions are also compared with elastic buckling stresses calculated on an element-by-element basis (i.e. ignoring the influence of element interaction). These comparisons are presented in Table 4.

\subsubsection{Case 1 - maximum compression in deeper I-section}

For three-flanged cross-sections where the maximum compression is within the deeper Isection (i.e. Case 1), it can be seen in Table 4 that the developed formulae provide accurate and safe-sided predictions of the numerical results: the mean value of the ratios of the predicted to numerical (CUFSM) elastic local buckling stresses of the three-flanged cross-sections is 0.945 with a $\mathrm{CoV}$ of 0.036 , compared to an equivalent mean prediction of 0.663 with a $\mathrm{CoV}$ of 0.099 when the elastic local buckling stress is calculated on an element-by-element basis, i.e. the developed formulae offer an average improvement in accuracy of about $30 \%$. The variation in prediction accuracy with $\phi_{\mathrm{d}}$ is shown in Fig. 20, and the frequency distributions for the predictions are shown in Fig. 21 (a).

\subsubsection{Case 2 - maximum compression in shallower I-section}

For three-flanged cross-sections where the maximum compression is within the shallower Isection (i.e. Case 2), similar improvements in prediction accuracy of around 30\% are achieved 
using the developed formulae in comparison to calculations performed on an element-byelement basis; the scatter of the predictions is also dramatically improved, as indicated by the $\mathrm{CoV}$ values given in Table 4, and the comparisons shown in Fig. 22 for the shallower section critical scenarios and Fig. 23 for the deeper section critical scenarios. The frequency distributions for the predictions are shown in Fig. 21 (b). The improvement in accuracy achieved through the use of the modified equation (Eq. (10)) for shallow shallower I-sections is small (around 2\%) on average, but can be significant (over 10\%) in some cases.

\subsection{Worked example}

A worked example is now presented to demonstrate application of the developed method for the determination of the elastic local buckling stress of a three-flanged cross-section in Case 2 . Note that the centreline geometry of the considered cross-section is used and fillets and corner radii are ignored.

A three-flanged cross-section made up of a UB $686 \times 254 \times 125$ beam profile in S355 steel with $E=210000 \mathrm{MPa}$ and $v=0.3$ subjected to a combination of compression $N_{\mathrm{Ed}}=1292 \mathrm{kN}$ and major axis bending $M_{\mathrm{y}, \mathrm{Ed}}=1000 \mathrm{kNm}$ is considered, as shown in Fig. 24. The maximum compression arises in the shallower section and we are thus considering Case 2. The distance between the neutral axis and the centreline of the top, bottom and middle flanges are denoted $z_{\mathrm{d}}, z_{\mathrm{s}}, z_{\mathrm{m}}$, respectively, while $A_{\mathrm{d}+\mathrm{s}}$ and $I_{\mathrm{d}+\mathrm{s}}$ are the area and major axis second moment of area of the compound (deeper + shallower) section. The stress distribution within the cross-section is first determined based on the applied loading and the section geometry, with compressive stresses taken as positive.

The applied stress at the top flange $\sigma_{2, \mathrm{dw}}$ is: 


$$
\begin{aligned}
\sigma_{2, \mathrm{dw}} & =\frac{N_{\mathrm{Ed}}}{A_{\mathrm{d}+\mathrm{s}}}-\frac{M_{\mathrm{Ed}} z_{\mathrm{d}}}{I_{\mathrm{d}+\mathrm{s}}} \\
& =\frac{1292 \times 10^{3}}{20452}-\frac{1000 \times 10^{6} \times 421.5}{1.723 \times 10^{9}} \\
& =-181.4 \mathrm{MPa} .
\end{aligned}
$$

The applied stress at the bottom flange $\sigma_{1, \mathrm{sw}}$ is:

$$
\begin{aligned}
\sigma_{1, \mathrm{sw}} & =\frac{N_{\mathrm{Ed}}}{A_{\mathrm{d}+\mathrm{s}}}+\frac{M_{\mathrm{Ed}} z_{\mathrm{s}}}{I_{\mathrm{d}+\mathrm{s}}} \\
& =\frac{1292 \times 10^{3}}{20452}+\frac{1000 \times 10^{6} \times 307.99}{1.723 \times 10^{9}} \\
& =241.9 \mathrm{MPa} .
\end{aligned}
$$

The applied stress at the middle flange $\sigma_{1, \mathrm{dw}}$ is:

$$
\begin{aligned}
\sigma_{1, \mathrm{dw}} & =\sigma_{2, \mathrm{sw}}=\frac{N_{\mathrm{Ed}}}{A_{\mathrm{d}+\mathrm{s}}}+\frac{M_{\mathrm{Ed}} z_{\mathrm{m}}}{I_{\mathrm{d}+\mathrm{s}}} \\
& =\frac{1292 \times 10^{3}}{20452}+\frac{1000 \times 10^{6} \times 240.2}{1.723 \times 10^{9}} \\
& =202.5 \mathrm{MPa} .
\end{aligned}
$$

Hence, the stress distributions in the web of the three-flanged cross-section $\psi_{\mathrm{dw}+\mathrm{sw}}$, the single deeper I-section $\psi_{\mathrm{dw}}$ and the single shallower I-section $\psi_{\mathrm{sw}}$ are respectively equal to:

$$
\begin{gathered}
\psi_{\mathrm{dw}+\mathrm{sw}}=\frac{\sigma_{2, \mathrm{dw}}}{\sigma_{1, \mathrm{sw}}}=\frac{-181.4}{241.9}=-0.750, \\
\psi_{\mathrm{dw}}=\frac{\sigma_{2, \mathrm{dw}}}{\sigma_{1, \mathrm{dw}}}=\frac{-181.4}{202.5}=-0.896, \\
\psi_{\mathrm{sw}}=\frac{\sigma_{2, \mathrm{sw}}}{\sigma_{1, \mathrm{sw}}}=\frac{202.5}{241.9}=0.837 .
\end{gathered}
$$

The flange plates are all in pure compression; hence:

$$
\psi_{\mathrm{df}}=\psi_{\mathrm{sf}}=1.0
$$

The elastic local buckling stress of the single deeper I-section is now calculated. First, the elastic local buckling stresses of the isolated deeper section flange and web with simply- 
supported and fixed boundary conditions are calculated. The buckling coefficients $k$ are obtained from Tables 1 and 2 .

For the deeper section flange $\left(\psi_{\mathrm{df}}=1\right), k_{\mathrm{df}}^{\mathrm{SS}}=0.43$ and $k_{\mathrm{df}}^{\mathrm{F}}=1.25$. Hence:

$$
\begin{aligned}
& \sigma_{\mathrm{cr}, \mathrm{df}}^{\mathrm{SS}}=k_{\mathrm{df}}^{\mathrm{SS}} \frac{\pi^{2} E}{12\left(1-v^{2}\right)}\left(\frac{t_{\mathrm{f}}}{0.5 b}\right)^{2}=0.43 \times \frac{210000 \pi^{2}}{12\left(1-0.3^{2}\right)}\left(\frac{16.2}{0.5 \times 253}\right)^{2}=1338.5 \mathrm{MPa} \\
& \sigma_{\mathrm{cr}, \mathrm{df}}^{\mathrm{F}}=k_{\mathrm{df}}^{\mathrm{F}} \frac{\pi^{2} E}{12\left(1-v^{2}\right)}\left(\frac{t_{\mathrm{f}}}{0.5 b}\right)^{2}=1.25 \times \frac{210000 \pi^{2}}{12\left(1-0.3^{2}\right)}\left(\frac{16.2}{0.5 \times 253}\right)^{2}=3890.9 \mathrm{MPa}
\end{aligned}
$$

For the deeper section web $\left(\psi_{\mathrm{dw}}=-0.896\right), k_{\mathrm{dw}}^{\mathrm{SS}}=21.30$ and $k_{\mathrm{dw}}^{\mathrm{F}}=35.54$. Hence:

$$
\begin{gathered}
\sigma_{\mathrm{cr}, \mathrm{dw}}^{\mathrm{SS}}=k_{\mathrm{dw}}^{\mathrm{SS}} \frac{\pi^{2} E}{12\left(1-v^{2}\right)}\left(\frac{t_{\mathrm{w}}}{h_{\mathrm{d}}-t_{\mathrm{f}}}\right)^{2}=21.30 \times \frac{210000 \pi^{2}}{12\left(1-0.3^{2}\right)}\left(\frac{11.7}{677.9-16.2}\right)^{2}=1263.9 \mathrm{MPa} \\
\sigma_{\mathrm{cr}, \mathrm{dw}}^{\mathrm{F}}=k_{\mathrm{dw}}^{\mathrm{F}} \frac{\pi^{2} E}{12\left(1-v^{2}\right)}\left(\frac{t_{\mathrm{w}}}{h_{\mathrm{d}}-t_{\mathrm{f}}}\right)^{2}=35.54 \times \frac{210000 \pi^{2}}{12\left(1-0.3^{2}\right)}\left(\frac{11.7}{677.9-16.2}\right)^{2}=2108.9 \mathrm{MPa}
\end{gathered}
$$

Since $\phi_{\mathrm{d}}=\sigma_{\mathrm{cr}, \mathrm{df}}^{\mathrm{SS}} / \sigma_{\mathrm{cr}, \mathrm{dw}}^{\mathrm{SS}}=1.059 \geq 1$, the web is the critical element in the deeper section, and the interaction coefficient for the deeper section $\zeta_{\mathrm{d}}$ is given by:

$$
\zeta_{\mathrm{d}}=\frac{t_{\mathrm{f}}}{t_{\mathrm{w}}}\left(0.45-\frac{0.3}{\phi_{\mathrm{d}}^{2}}\right)=\frac{16.2}{11.7} \times\left(0.45-\frac{0.3}{1.059^{2}}\right)=0.253
$$

The elastic local buckling stresses of the critical plate in the deeper section with simplysupported and fixed boundary conditions are respectively equal to:

$$
\begin{aligned}
& \sigma_{\mathrm{cr}, \mathrm{dp}}^{\mathrm{SS}}=\min \left(\sigma_{\mathrm{cr}, \mathrm{df}}^{\mathrm{SS}}, \sigma_{\mathrm{cr}, \mathrm{dw}}^{\mathrm{SS}}\right)=1263.9 \mathrm{MPa} \\
& \sigma_{\mathrm{cr}, \mathrm{dp}}^{\mathrm{F}}=\min \left(\sigma_{\mathrm{cr}, \mathrm{df}}^{\mathrm{F}}, \sigma_{\mathrm{cr}, \mathrm{dw}}^{\mathrm{F}}\right)=2108.9 \mathrm{MPa}
\end{aligned}
$$

Thus, the elastic local buckling stress of the deeper section is:

$$
\sigma_{\mathrm{cr}, \mathrm{d}}=\sigma_{\mathrm{cr}, \mathrm{dp}}^{\mathrm{sS}}+\zeta_{\mathrm{d}}\left(\sigma_{\mathrm{cr}, \mathrm{dp}}^{\mathrm{F}}-\sigma_{\mathrm{cr}, \mathrm{dp}}^{\mathrm{ss}}\right)=1263.9+0.253 \times(2108.9-1263.9)=1477.7 \mathrm{MPa} .
$$


Applying the same process, the elastic local buckling stress of the single shallower I-section can be obtained. The buckling coefficients of the isolated shallower section flange and web plates with simply-supported and fixed boundary conditions are $k_{\mathrm{sf}}^{\mathrm{SS}}=0.43, k_{\mathrm{sf}}^{\mathrm{F}}=1.25$, $k_{\mathrm{sw}}^{\mathrm{SS}}=4.35, k_{\mathrm{sw}}^{\mathrm{F}}=7.57$. The corresponding elastic local buckling stresses of the isolated shallower section flange and web plates are equal to $\sigma_{\mathrm{cr}, \mathrm{sf}}^{\mathrm{sS}}=1338.5 \mathrm{MPa}, \sigma_{\mathrm{cr}, \mathrm{sf}}^{\mathrm{F}}=3890.9 \mathrm{MPa}$, $\sigma_{\mathrm{cr}, \mathrm{sw}}^{\mathrm{ss}}=24593.8 \mathrm{MPa}, \sigma_{\mathrm{cr}, \mathrm{sw}}^{\mathrm{F}}=42798.9 \mathrm{MPa}$. Since $\phi_{\mathrm{s}}=\sigma_{\mathrm{cr}, \mathrm{sf}}^{\mathrm{ss}} / \sigma_{\mathrm{cr}, \mathrm{sw}}^{\mathrm{sS}}=0.054<1$, the flange is the critical element in the shallower section. Since the dimension ratio of this shallower section $\left(\left(h_{\mathrm{s}}+t_{\mathrm{f}}\right) / t_{\mathrm{w}}\right)\left(t_{\mathrm{f}} / b\right)=0.460<0.89$, the interaction coefficient is calculated using Eq. (10) as follows.

$$
\begin{aligned}
\zeta_{\mathrm{s}} & =\max \left(0.15 \frac{t_{\mathrm{f}}}{t_{\mathrm{w}}} \phi_{\mathrm{s}}, \frac{t_{\mathrm{w}}}{t_{\mathrm{f}}}\left(0.4-0.25 \phi_{\mathrm{s}}\right)\right)+0.4\left(0.89-\frac{h_{\mathrm{s}}+t_{\mathrm{f}}}{t_{\mathrm{w}}} \frac{t_{\mathrm{f}}}{b}\right)^{2} \\
& =\max \left(0.15 \times \frac{16.2}{11.7} \times 0.054, \frac{11.7}{16.2}(0.4-0.25 \times 0.054)\right)+0.4\left(0.89-\frac{83.99}{11.7} \frac{16.2}{253}\right)^{2} \\
& =0.353
\end{aligned}
$$

Thus, the elastic local buckling stress of the shallower I-section is given by:

$$
\sigma_{\mathrm{cr}, \mathrm{s}}=\sigma_{\mathrm{cr}, \mathrm{sp}}^{\mathrm{ss}}+\zeta_{\mathrm{s}}\left(\sigma_{\mathrm{cr}, \mathrm{sp}}^{\mathrm{F}}-\sigma_{\mathrm{cr}, \mathrm{sp}}^{\mathrm{ss}}\right)=1338.5+0.353 \times(3890.9-1338.5)=2239.5 \mathrm{MPa}
$$

Hence, the critical load factors of the deeper and shallower I-sections are respectively equal to $\alpha_{\mathrm{cr}, \mathrm{d}}=\sigma_{\mathrm{cr}, \mathrm{d}} / \psi_{\mathrm{sw}}=1765.5 \mathrm{MPa}$ and $\alpha_{\mathrm{cr}, \mathrm{s}}=\sigma_{\mathrm{cr}, \mathrm{s}}=2239.5 \mathrm{MPa}$. Since $\gamma=\alpha_{\mathrm{cr}, \mathrm{s}} / \alpha_{\mathrm{cr}, \mathrm{d}}=1.268 \geq 1$, the scenario is classified as deeper section critical. Considering the beneficial effect from the shallower section on the critical deeper section as follows,

$$
\zeta_{\mathrm{s}}^{*}=3.7 \frac{t_{\mathrm{f}}}{t_{\mathrm{w}}}\left(1-\psi_{\mathrm{sw}}^{2}\right)\left(1-\frac{1}{\gamma}\right) / \phi_{\mathrm{d}}^{2}=3.7 \frac{16.2}{11.7}\left(1-0.837^{2}\right)\left(1-\frac{1}{1.268}\right) / 1.059^{2}=0.289
$$

the compound interaction coefficient of the three-flanged cross-section is equal to:

$$
\zeta_{\mathrm{d}+\mathrm{s}}=\zeta_{\mathrm{d}}+\zeta_{\mathrm{s}}^{*}=0.253+0.289=0.542
$$

Hence, the elastic local buckling stress of the three-flanged cross-section is given by: 


$$
\begin{aligned}
\sigma_{\mathrm{cr}, \mathrm{d}+\mathrm{s}} & =\left[\sigma_{\mathrm{cr}, \mathrm{dp}}^{\mathrm{SS}}+\zeta_{\mathrm{d}+\mathrm{s}}\left(\sigma_{\mathrm{cr}, \mathrm{dp}}^{\mathrm{F}}-\sigma_{\mathrm{cr}, \mathrm{dp}}^{\mathrm{sS}}\right)\right] / \psi_{\mathrm{sw}} \\
& =[1263.9+0.542 \times(2108.9-1263.9)] / 0.837 \\
& =2057.2 \mathrm{MPa} .
\end{aligned}
$$

The elastic local buckling stress of this three-flanged cross-section obtained from CUFSM is 2104.4 MPa, only 2.2\% higher than the predicted value. On an element-by-element basis, the critical elastic local buckling stress of the three-flanged cross-section, (as controlled by the shallower section flange) is $1338.5 \mathrm{MPa}, 34 \%$ below the prediction attained using the proposed formulae. Note that although the deeper section web has a lower elastic buckling stress than the shallower section flange, the deeper section web is subjected to a lower compressive stress and is not the critical element (as indicated by the higher critical load factor). The presented calculation involves a number of steps, but the formulae are both transparent in their purpose and straightforward, making them readily suitable for programming.

\section{Conclusions}

Formulae for calculating the elastic local buckling stress of three-flanged cross-sections have been developed and presented herein. The geometry and loading of the studied cross-sections have been assumed to be constant along the member length, i.e. the influence of tapering and moment gradients has not been considered, but the current work provides the basis for exploration of these effects in future research. The formulae were benchmarked against numerical results generated by means of finite strip analysis on a total of 9000 three-flanged cross-sections subjected to combined loading conditions ranging from pure compression to pure major axis bending; corresponding single deeper and shallower sections were also analysed under same stress conditions as in the three-flanged cross-section to aid the assessment of the results. It was found that, similar to the element interaction observed between the flange and web within single I-sections, in the case of three-flanged cross-sections, the deeper and shallower sections also interact with each other, i.e. the non-critical part is able to provide rotational restraint to the critical part. Two cases were considered - Case 1, where the 
maximum compression arises in the deeper section and Case 2, where the maximum compression arises in the shallower section; predictive formulae were developed for both cases, allowing for the interaction both within and between the deeper and shallower I-sections. Using the developed formulae, predictions of the elastic local buckling stress of three-flanged crosssections were shown to be typically within $5 \%$ of the numerically obtained values, around $30 \%$ higher than calculations performed on an element-by-element basis. The formulae can be used to facilitate the more efficient design of structures that feature three-flanged cross-sections, such as continuous and longitudinally-stiffened plate girders and portal frames, and their application was demonstrated through a worked example.

\section{Acknowledgement}

The financial support provided by the China Scholarship Council (CSC) for the first author is gratefully acknowledged.

\section{References}

[1] Gardner L, Fieber A, Macorini L. Formulae for calculating elastic local buckling stresses of full structural cross-sections. Structures 2019;17:2-20.

[2] Quan C, Kucukler M, Gardner L. Design of web-tapered steel I-section members by second-order inelastic analysis with strain limits. Eng Struct 2020, Submitted.

[3] Li Z, Schafer BW. Buckling analysis of cold-formed steel members with general boundary conditions using CUFSM: conventional and constrained finite strip methods. Twentieth international speciality conference on cold-formed steel structures. Saint Louis, Missouri, USA; 2010.

[4] EN 1993-1-1. Eurocode 3: design of steel structures - part 1-1: general rules and rules for buildings. Brussels: European Committee for Standardization; 2005.

[5] AISC 360-16. Specification for structural steel buildings. American Institute of Steel Construction; 2016. 
[6] Schafer BW. Review: the direct strength method of cold-formed steel member design. J Constr Steel Res 2008;64:766-778.

[7] Committee on Specifications for the Design of Cold-Formed Steel Structural Members. Direct strength method (DSM) design guide. American Iron and Steel Institute; 2006.

[8] Gardner L. The continuous strength method. Proc Inst Civ Eng Struct Build 2008;161(3):127-33.

[9] Afshan S, Gardner L. The continuous strength method for structural stainless steel design. Thin-Walled Struct 2013;68:42-49.

[10] Gardner L, Wang F, Liew A. Influence of strain hardening on the behavior and design of steel structures. International Journal of Structural Stability and Dynamics 2011;11(5):855-875.

[11] Seif M, Schafer BW. Local buckling of structural steel shapes. J Constr Steel Res 2010;66(10):1232-1247.

[12] Lundquist E, Stowell E. Critical compressive stress for flat rectangular plates sup- ported along all edges and elastically restrained against rotation along the unloaded edges. National Advisory Committee for Aeronautics, special report 189. 1941.

[13] Lundquist E, Stowell E. Critical compressive stress for outstanding flanges. National Advisory Committee for Aeronautics, report no. 734. 1942.

[14] Johnson D. An investigation into the interaction of flanges and webs in wide flange shapes Cleveland (OH). Proceedings SSRC annual technical session1985. p. 395-405.

[15] Möller M. Local flange buckling. Ph.D. thesis Lulea University of Technology; 1995.

[16] Bedair O. Stability of web plates in W-shape columns accounting for flange/web interaction. Thin-Walled Struct 2009;47:768-775.

[17] Han KH, Lee CH. Elastic flange local buckling of I-shaped beams considering effect of web restraint. Thin-Walled Struct 2016;105:101-111. 
[18] Marques L. Tapered steel members: flexural and lateral-torsional buckling. Ph.D. thesis University of Coimbra; 2012.

[19] Marques L, Simões Da Silva L, Greiner R, Rebelo C, Taras A. Development of a consistent design procedure for lateral-torsional buckling of tapered beams. J Constr Steel Res 2013;89:213-35.

[20] Tankova T, Simões da Silva L, Marques L. Buckling resistance of non-uniform steel members based on stress utilization: General formulation. J Constr Steel Res 2018;149:239-56.

[21] Kucukler M, Gardner L. Design of laterally restrained web-tapered steel structures through a stiffness reduction method. J Constr Steel Res 2018;141:63-76.

[22] Kucukler M, Gardner L. Design of web-tapered steel beams against lateral-torsional buckling through a stiffness reduction method. Eng Struct 2019;190:246-61.

[23] Lay MG, Galambos TV. The inelastic behavior of beams under moment gradient. Fritz Engineering Laboratory Report No. 297.12. Lehigh University; 1964.

[24] Lay MG. Some studies of flange local buckling in wide-flange shapes. Fritz Engineering Laboratory Report No. 297.10. Lehigh University; 1964.

[25] Fieber A, Gardner L, Macorini L. Design of structural steel members by advanced inelastic analysis with strain limits. Eng Struct 2019;199:109624.

[26] Lu Y, Li W, Zhou T, Wu H. Novel local buckling formulae for cold-formed C-section columns considering end condition effect. Thin-Walled Struct 2017;116:265-276.

[27] Fieber A, Gardner L, Macorini L. Formulae for determining elastic local buckling halfwavelengths of structural steel cross-sections. J Constr Steel Res 2019;159:493-506.

[28] EN 1993-1-5. Eurocode 3: design of steel structures - part 1-5: plated structural elements. Brussels: European Committee for Standardization; 2006. 
[29] Gardner L, Yun X, Fieber A, Macorini L. Steel Design by Advanced Analysis: Material Modeling and Strain Limits. Engineering 2019;5:243-249.

[30] Fieber A, Gardner L, Macorini L. Structural steel design using second-order inelastic analysis with strain limits. J Constr Steel Res 2020;168:105980.

[31] Li Z, Schafer BW. Application of the finite strip method in cold-formed steel member design. J Constr Steel Res 2010;66:971-980. 


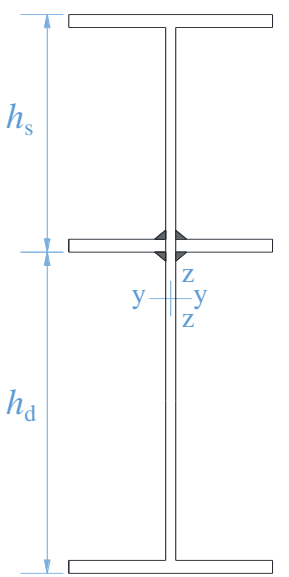

(a) Longitudinally-stiffened plate girder
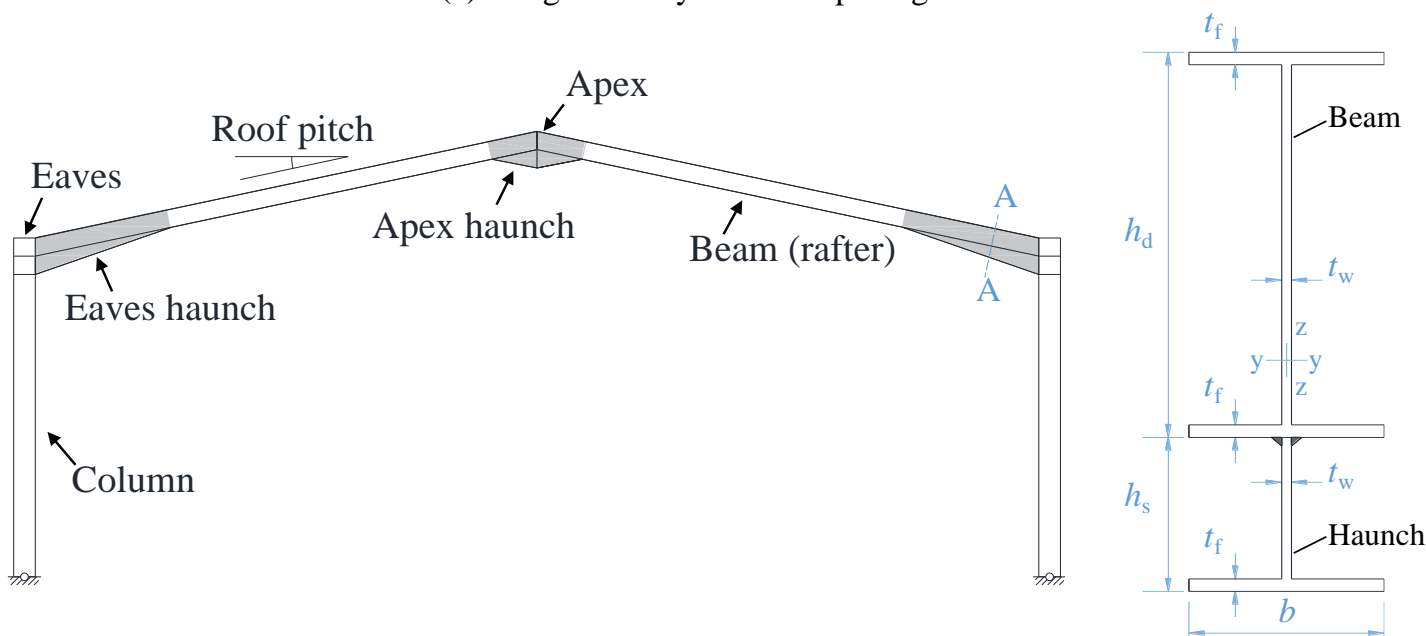

(b) Steel portal frame

(c) Geometry of crosssection at A-A

Fig. 1 Examples of steel members with three-flanged cross-sections 


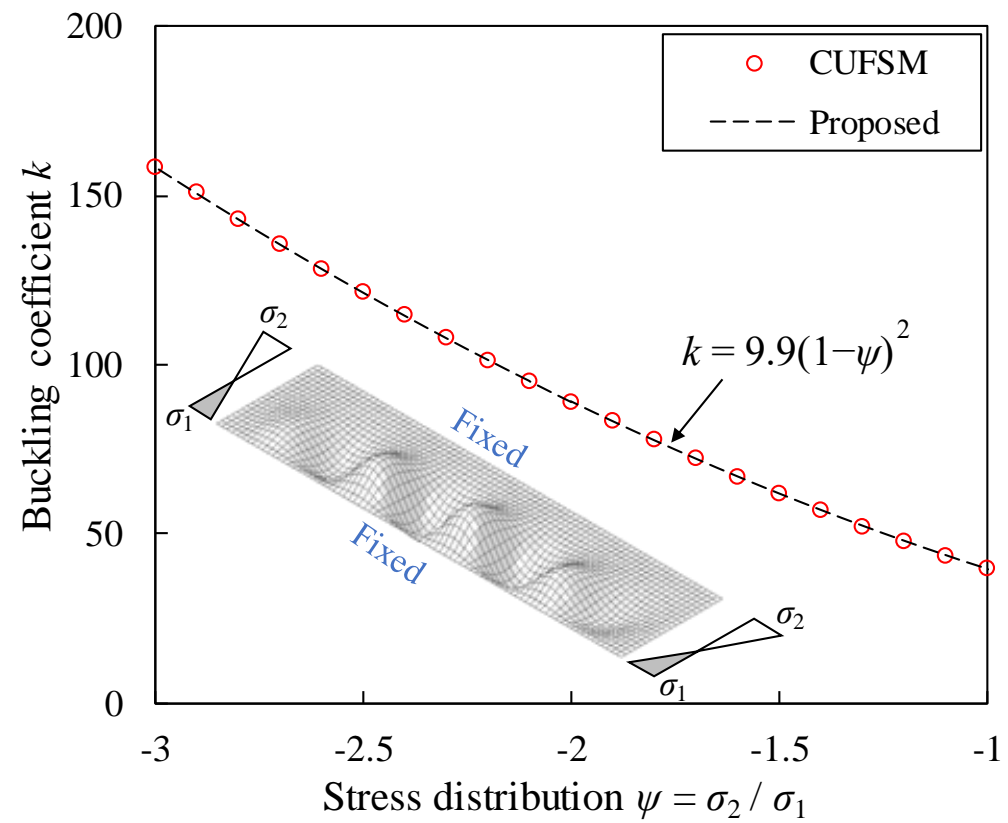

Fig. 2 Buckling coefficient $k$ for internal elements with fixed boundary conditions along longitudinal edges with $-3 \leq \psi<-1$ 


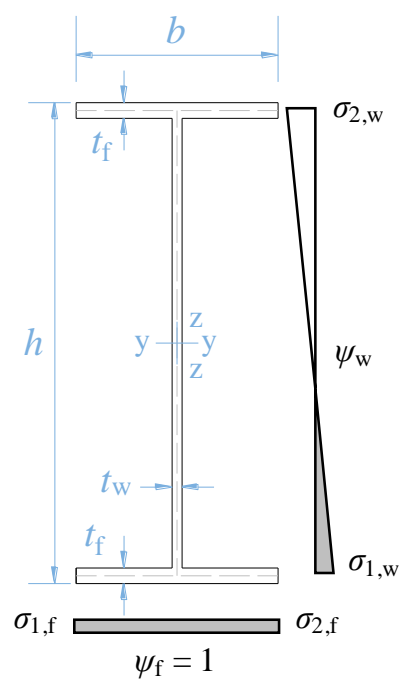

Fig. 3 Geometry, notation and stress distribution in an I-section under compression and major axis bending 


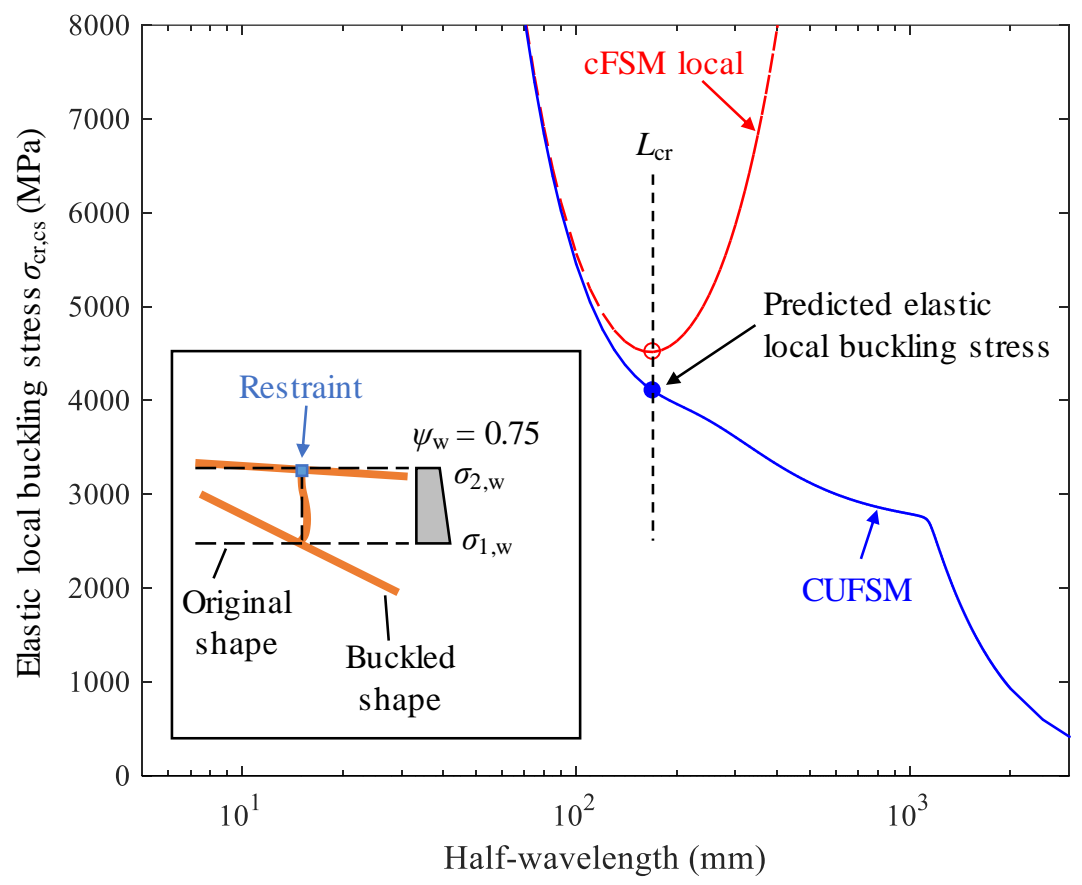

Fig. 4 Signature curves obtained using cFSM and CUFSM and method to determine elastic local buckling stress in the absence of a distinct minimum in CUFSM results 


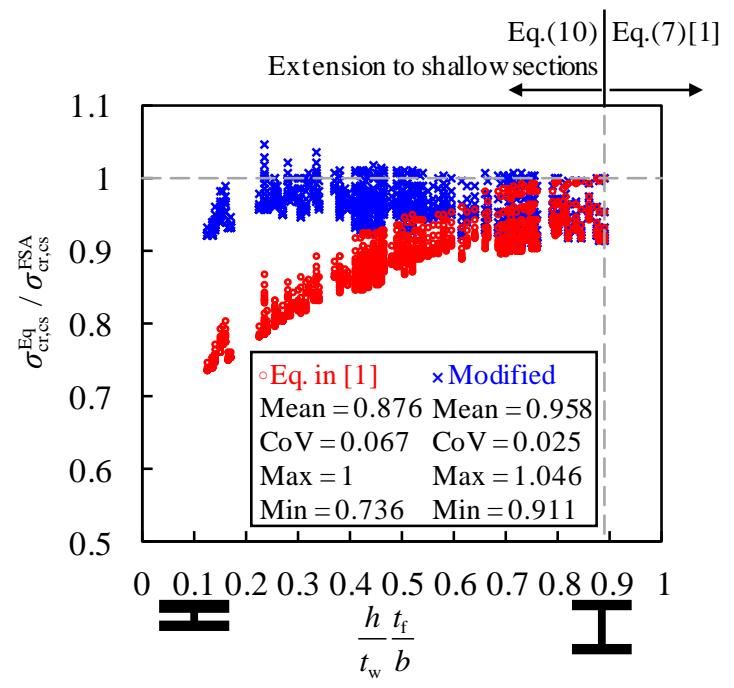

(a) Calculated elastic local buckling stresses using equations in [1] or modified equations, compared against results obtained from FSA

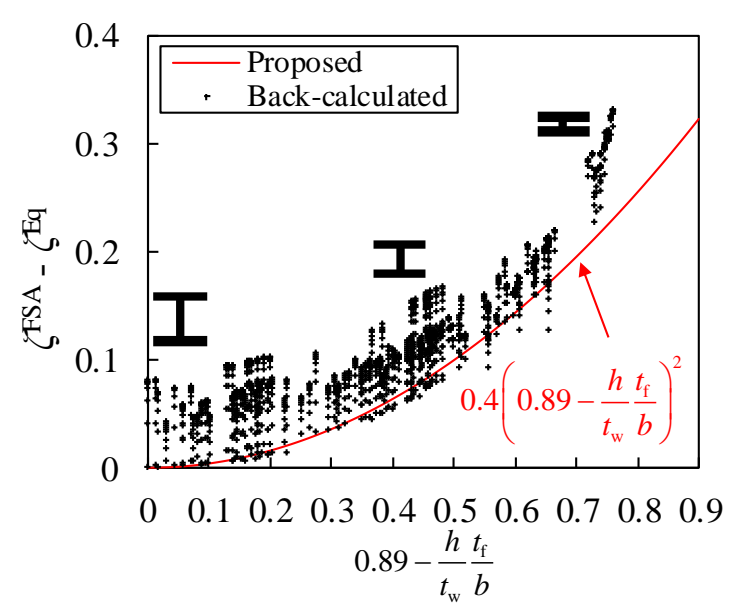

(b) Calibration of proposed modification factor for shallow I-sections

Fig. 5 Elastic local buckling stresses and interaction coefficient $\zeta$ for shallow I-sections with $\frac{h}{t_{\mathrm{w}}} \frac{t_{\mathrm{f}}}{b}<0.89$ 


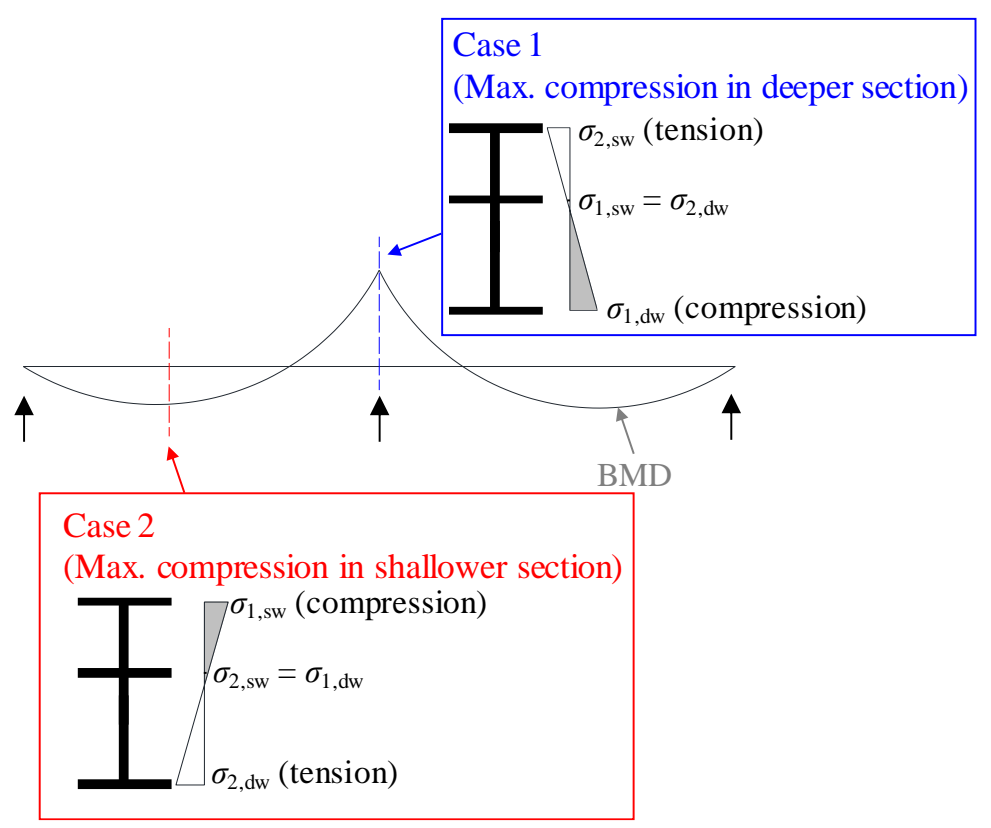

(a) Continuous and longitudinally-stiffened plate girder

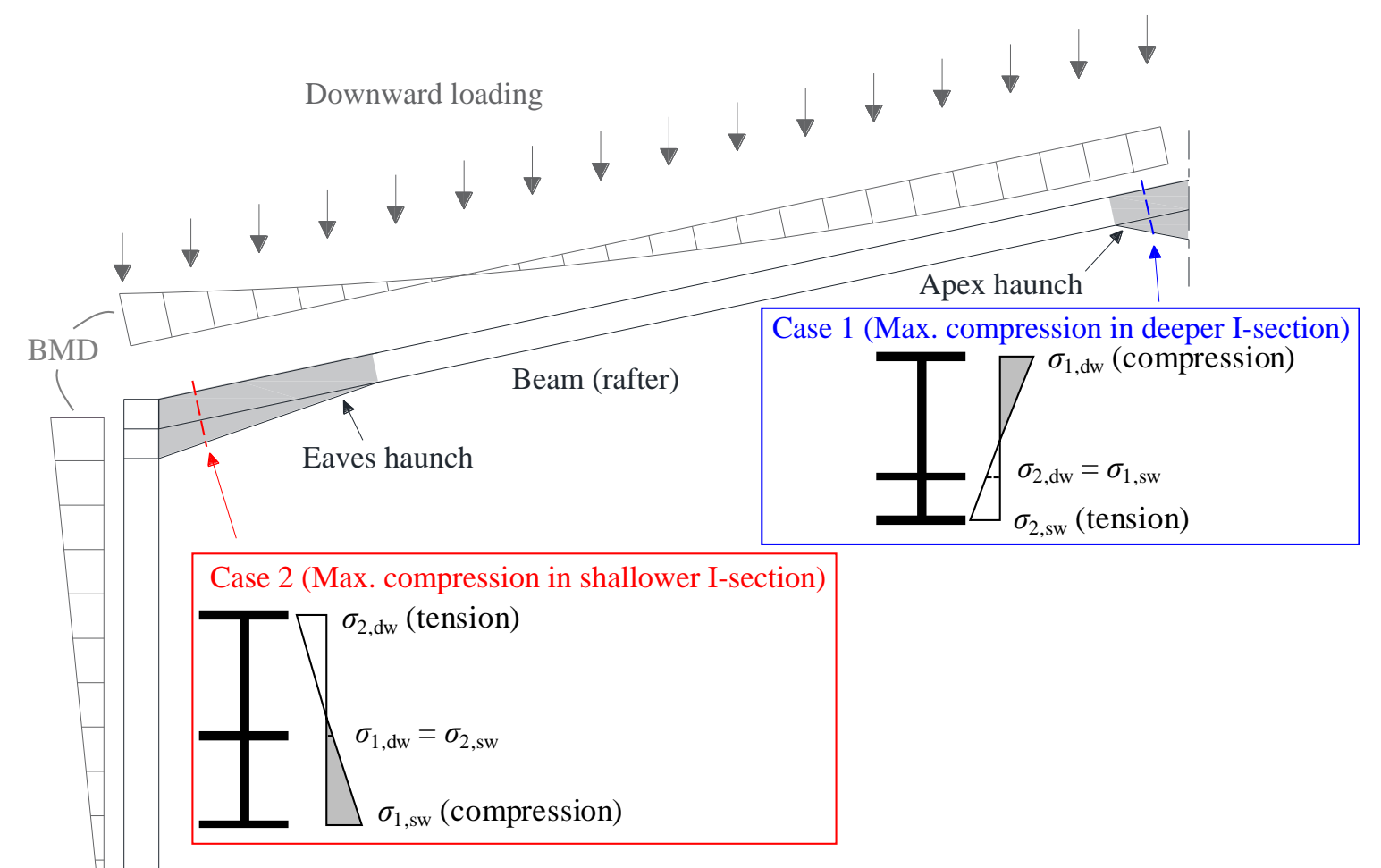

Column

(b) Portal frames under downward loading 


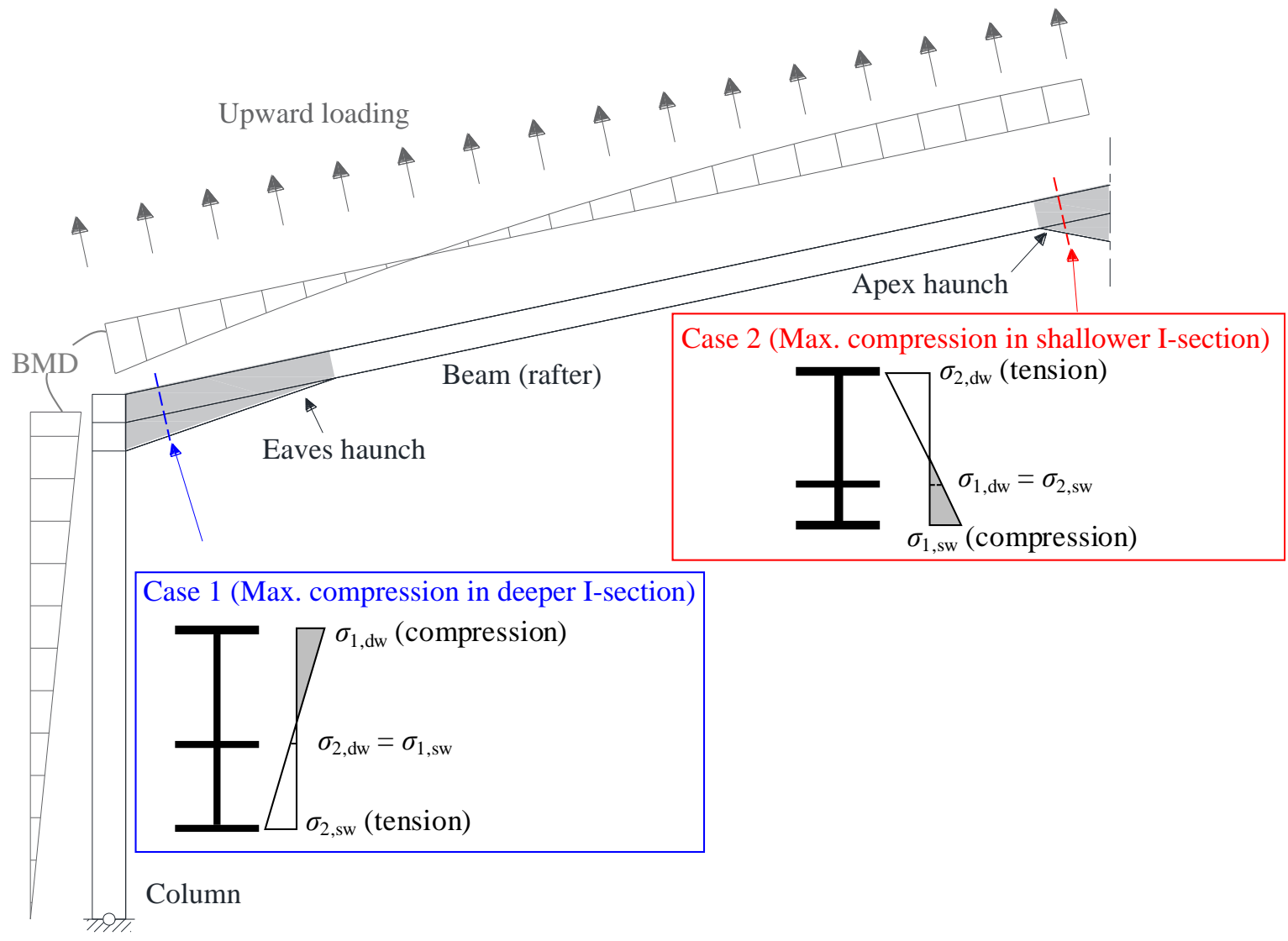

(c) Portal frame under upward loading

Fig. 6 Typical loading conditions with corresponding bending moment diagrams (BMD) of (a) the continuous and longitudinally-stiffened plate girder and (b) the beam (rafter) of portal frames under downward loading and (c) upward loading 
Boundary condition: $\mathrm{SS}=$ simply supported, $\mathrm{F}=$ fixed

$\left.\sigma \frac{\mathrm{SS}}{\mathrm{cr}}\right]$

$\mathrm{p}=$ isolated plate $(\mathrm{f}=$ flange, $\mathrm{w}=\mathrm{web})$

$\mathrm{dp}=$ isolated plate of deeper section

$(\mathrm{df}=$ flange of deeper section, $\mathrm{dw}=$ web of deeper section $)$

$\mathrm{sp}=$ isolated plate of shallower section

( $\mathrm{sf}=$ flange of shallower section, $\mathrm{sw}=$ web of shallower section $)$

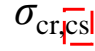

cs $=$ cross-section

$\mathrm{d}=$ deeper section, $\mathrm{s}=$ shallower section, $\mathrm{d}+\mathrm{s}=$ full three-flanged section

$\sigma_{11}, \mathrm{w}$

$1=$ maximum compressive stress

$2=$ minimum compressive or maximum tensile stress

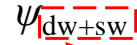

$\mathrm{dw}+\mathrm{sw}=\mathrm{web}$ of full three-flanged section

Fig. 7 Definitions of superscript and subscript notation 


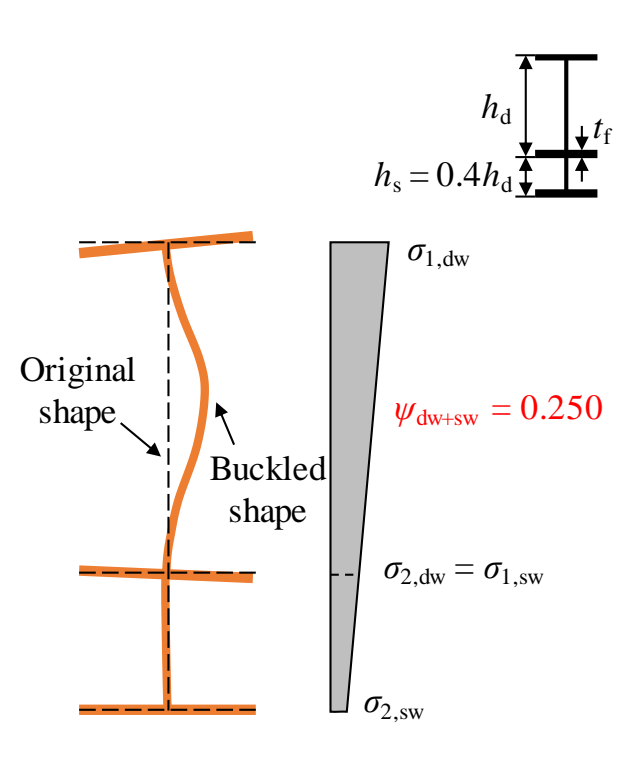

(a) $\alpha_{\mathrm{cr}, \mathrm{d}+\mathrm{s}}=756.9 \mathrm{MPa}$

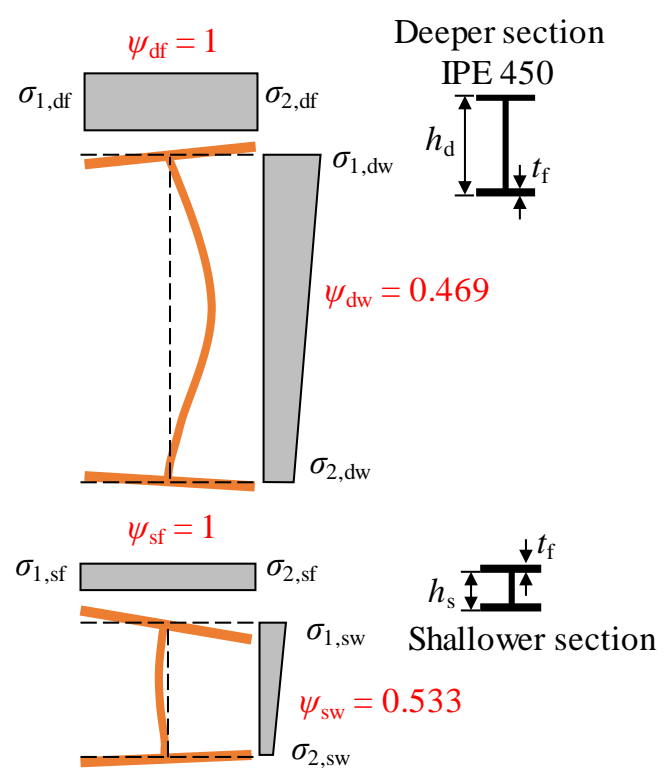

(b) $\alpha_{\mathrm{cr}, \mathrm{d}}=749.7 \mathrm{MPa} ; \alpha_{\mathrm{cr}, \mathrm{s}}=5573.4 \mathrm{MPa}$

Fig. 8 A Case 1 (deeper section critical) example of stress distributions, local buckling shapes and critical local buckling load factors of (a) a three-flanged cross-section and (b) the corresponding single deeper and shallower I-sections 


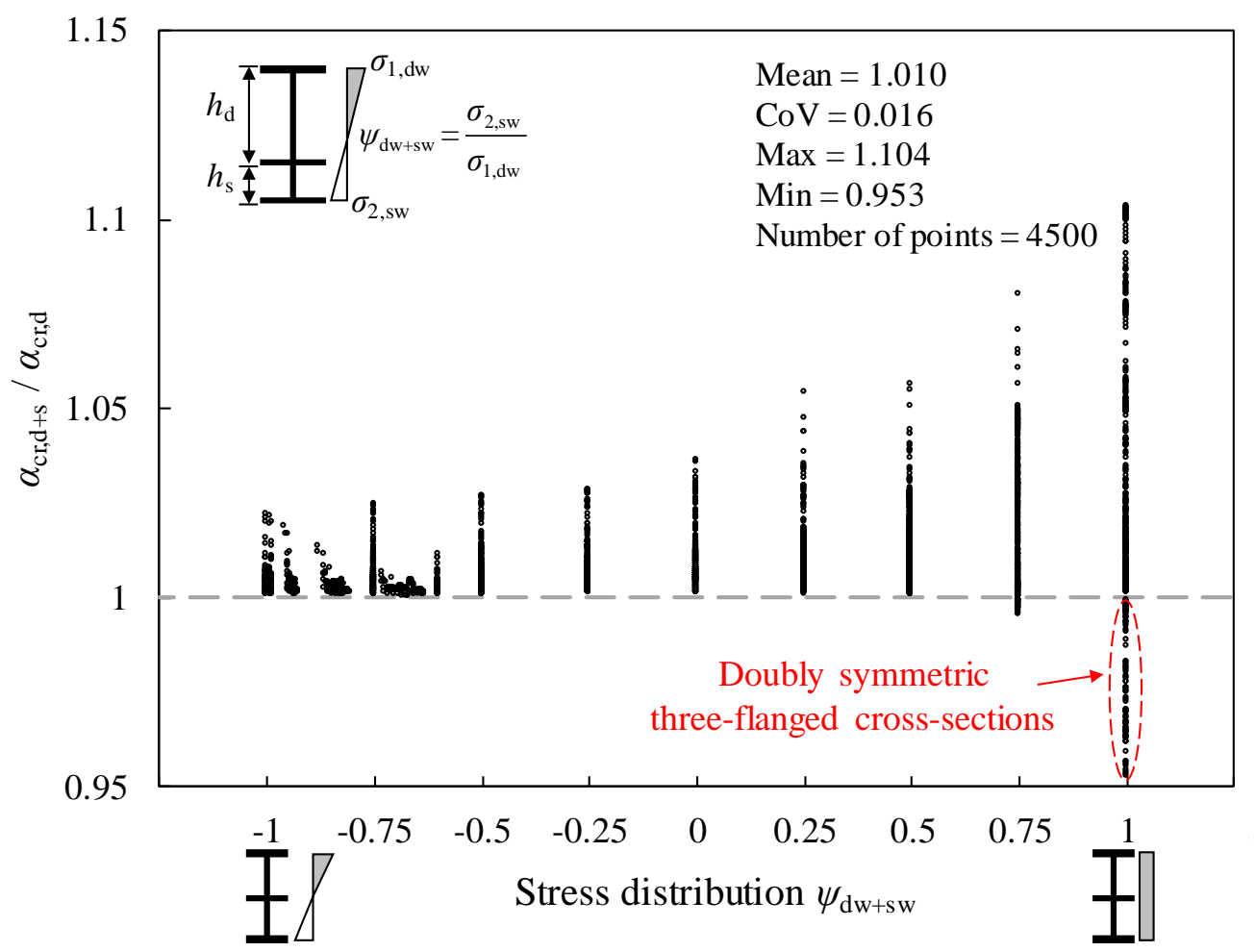

Fig. 9 CUFSM results showing influence of shallower I-section on local buckling stress of three-flanged crosssection in Case 1 


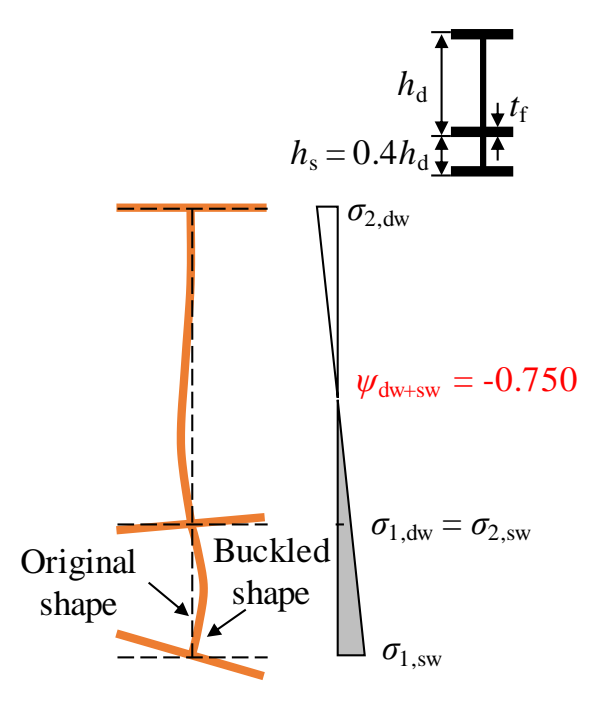

(a) $\quad \alpha_{\mathrm{cr}, \mathrm{d}+\mathrm{s}}=2635.0 \mathrm{MPa}$

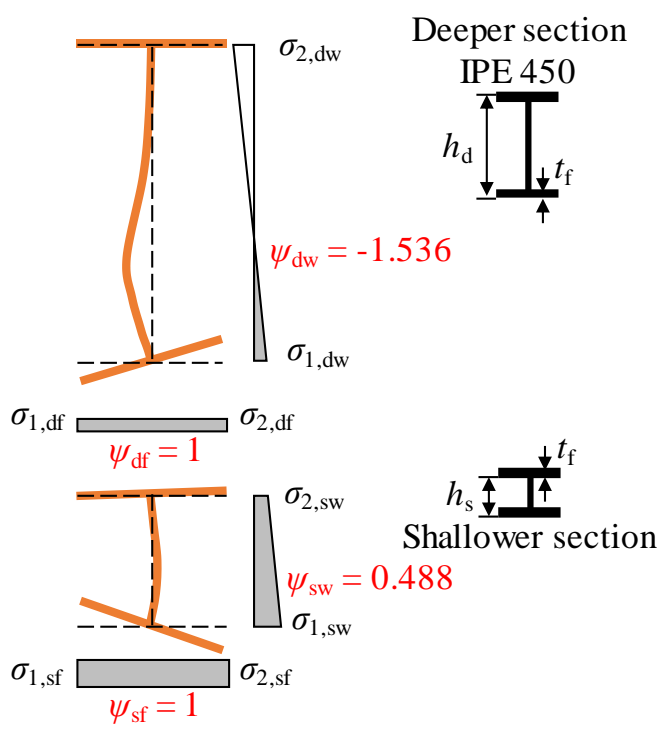

(b) $\alpha_{\mathrm{cr}, \mathrm{d}}=4997.7 \mathrm{MPa} ; \alpha_{\mathrm{cr}, \mathrm{s}}=2623.4 \mathrm{MPa}$

Fig. 10 A Case 2 (shallower section critical) example of stress distributions, local buckling shapes and critical local buckling load factors of (a) a three-flanged cross-section and (b) the corresponding single deeper and shallower I-sections 


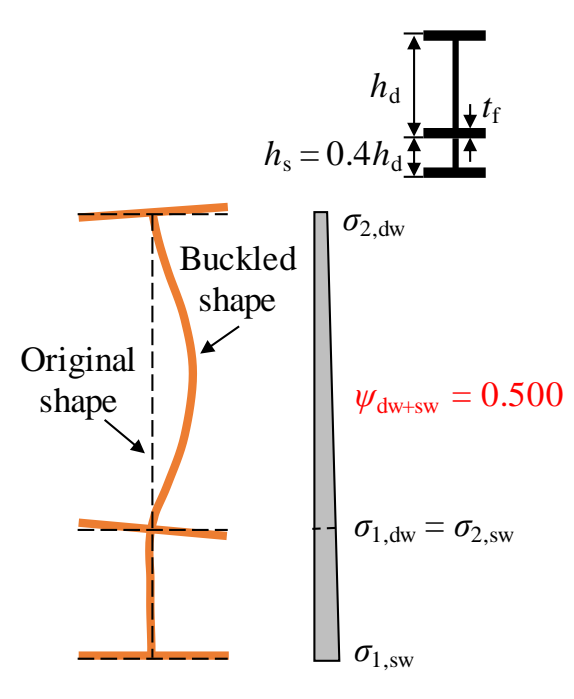

(a) $\alpha_{\mathrm{cr}, \mathrm{d}+\mathrm{s}}=828.1 \mathrm{MPa}$

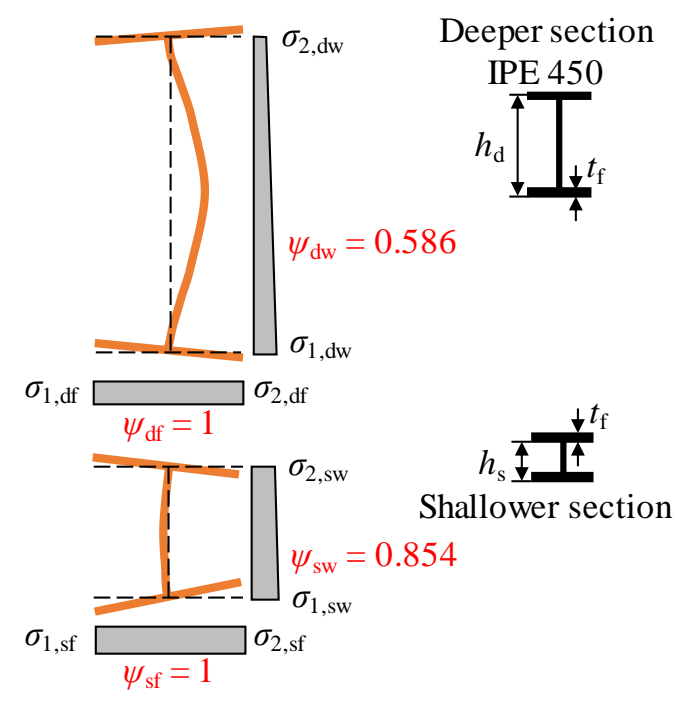

(b) $\alpha_{\mathrm{cr}, \mathrm{d}}=816.0 \mathrm{MPa} ; \alpha_{\mathrm{cr}, \mathrm{s}}=2481.5 \mathrm{MPa}$

Fig. 11 A Case 2 (deeper section critical) example of stress distributions, local buckling shapes and critical local buckling load factors of (a) a three-flanged cross-section and (b) the corresponding single deeper and shallower I-sections 


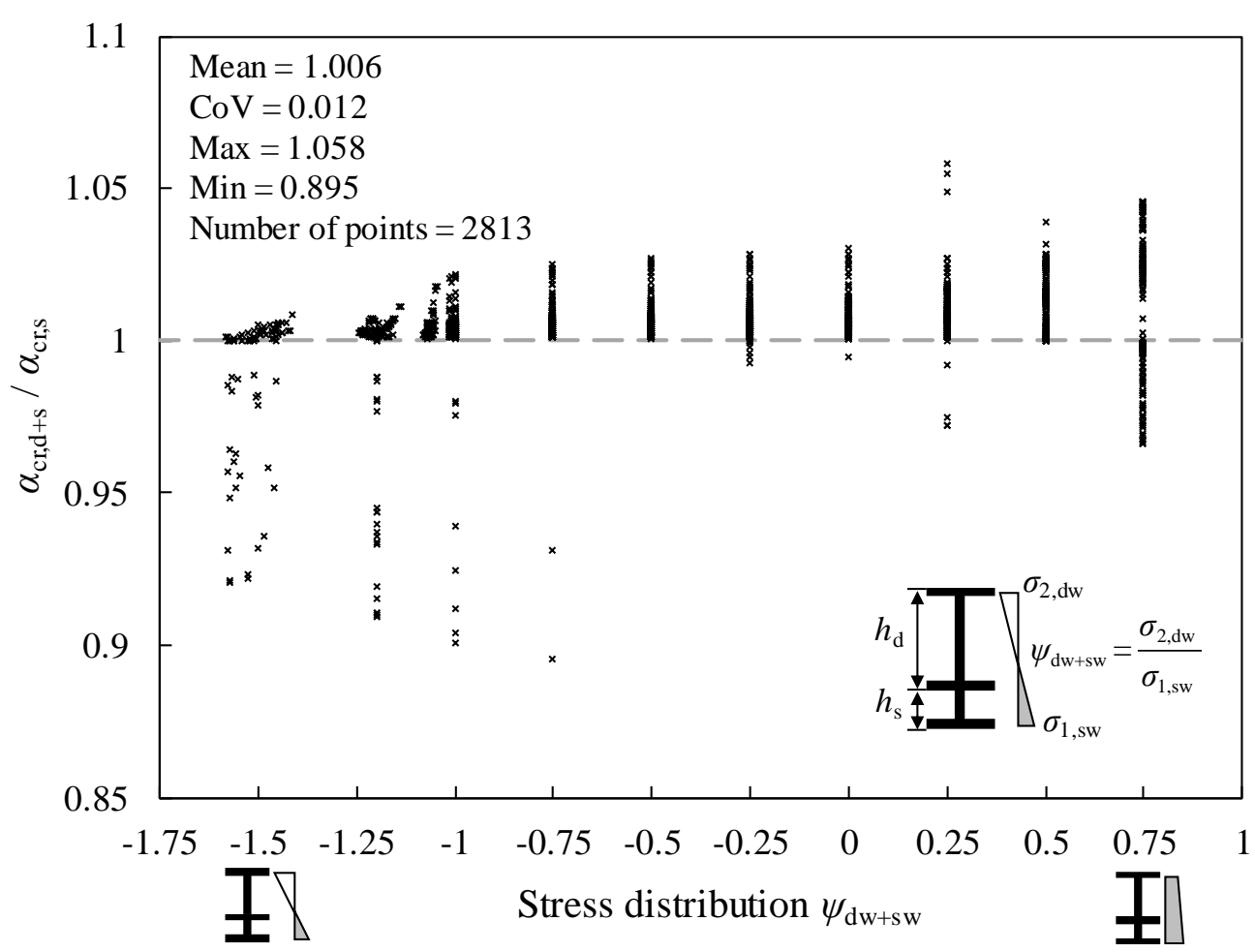

Fig. 12 CUFSM results showing influence of deeper section on critical shallower section, for shallower section critical scenarios in Case 2 


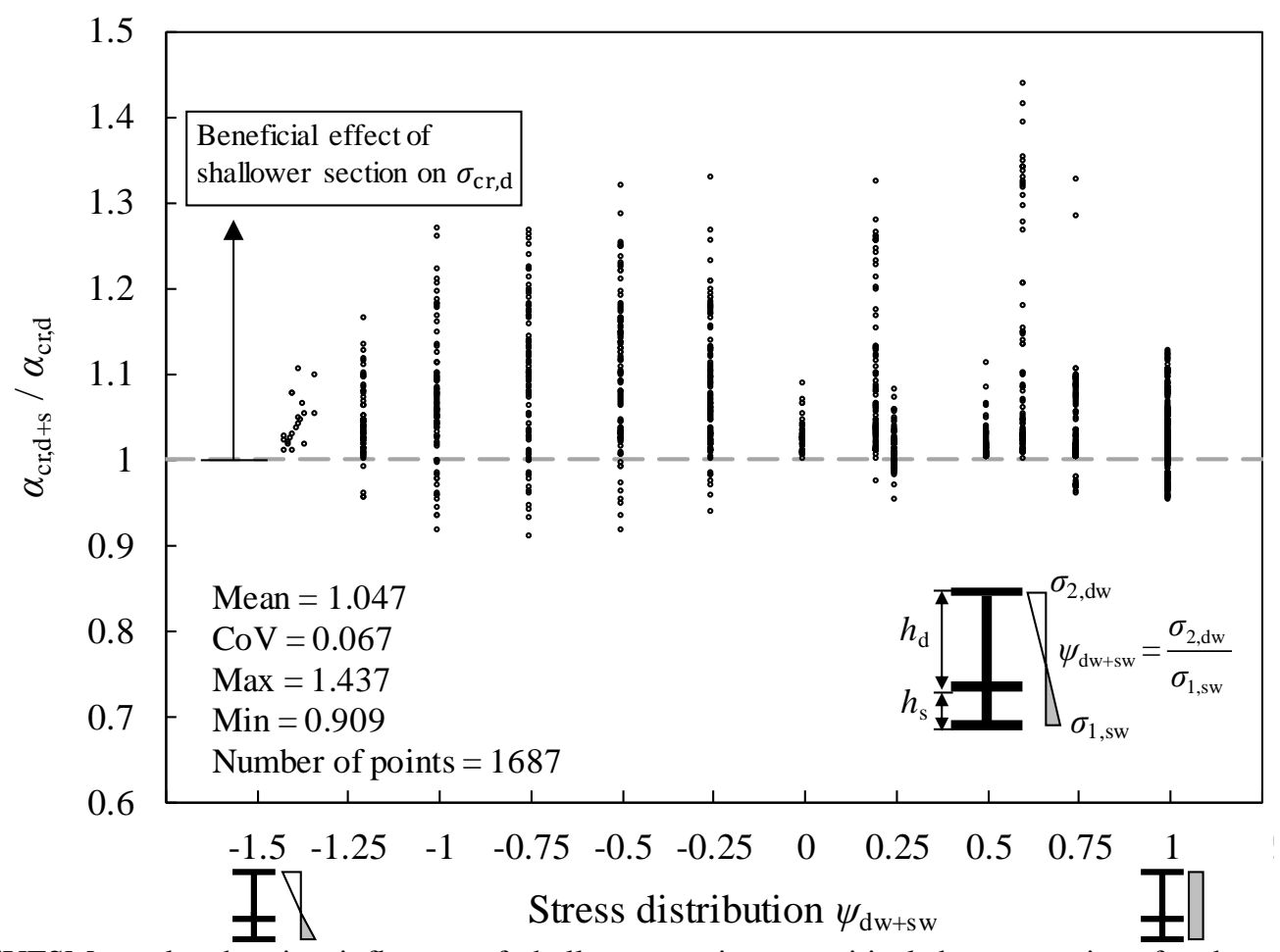

Fig. 13 CUFSM results showing influence of shallower section on critical deeper section, for deeper section critical scenarios in Case 2 with varying stress distributions 


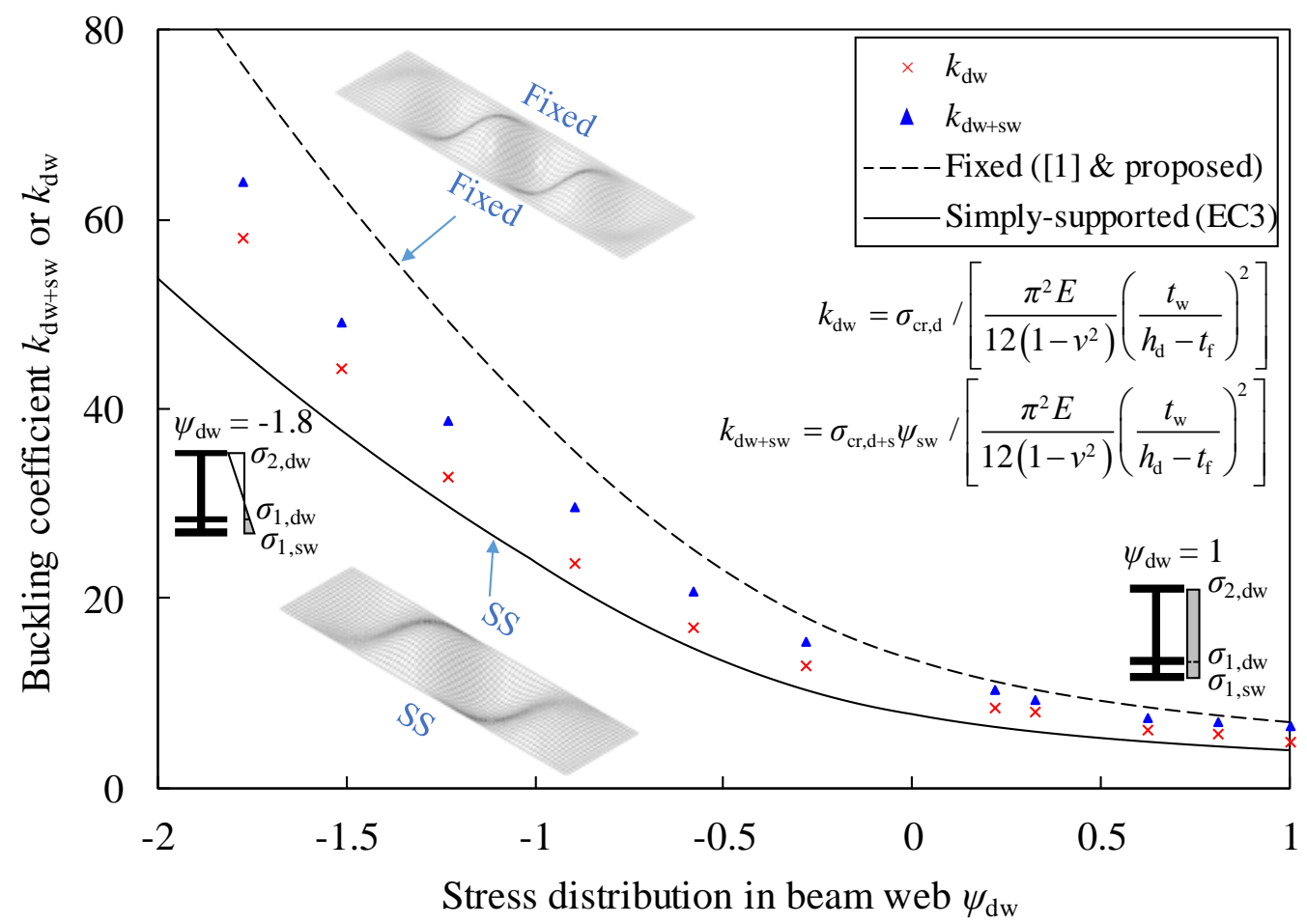

Fig. 14 Back-calculated buckling coefficients of the web in single deeper I-sections $k_{\mathrm{dw}}$ and in corresponding three-flanged cross-sections $k_{\mathrm{dw}+\mathrm{sw}}$ (when the web in deeper sections is the critical plate); the lower and upper bound buckling coefficient values of the isolated web with simply-supported and fixed boundary conditions along the longitudinal edges are also shown. 


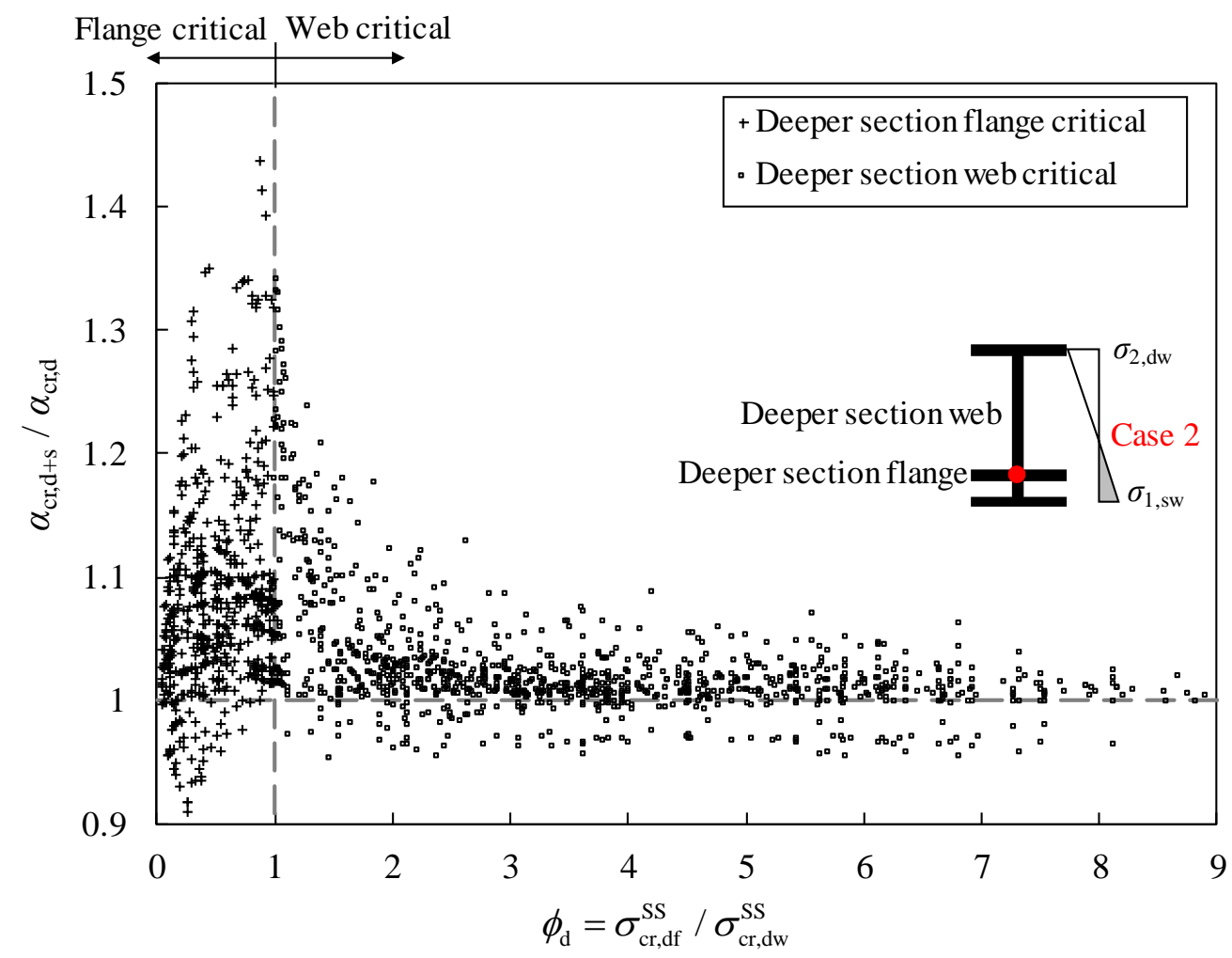

Fig. 15 CUFSM results showing influence of shallower section on critical deeper section, for deeper section critical scenarios in Case 2 with varying $\phi_{\mathrm{d}}$ values 


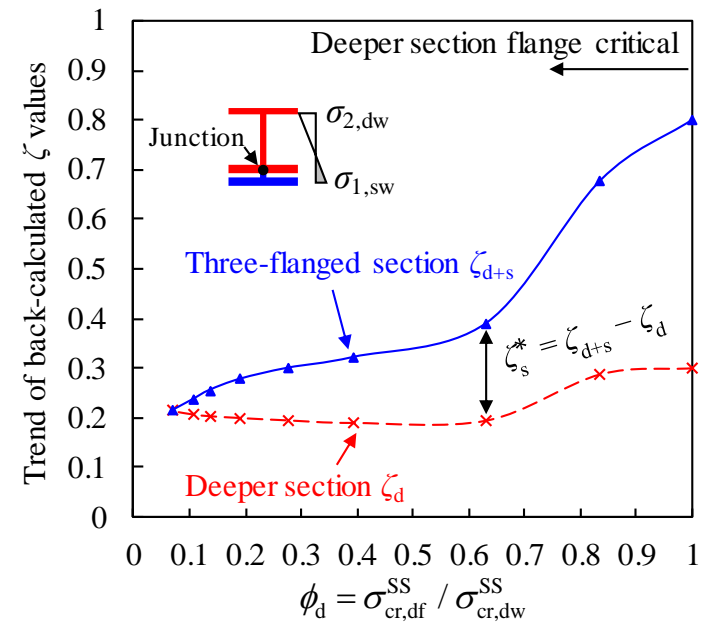

(a) Deeper section flange critical $\left(\phi_{\mathrm{d}}<1\right)$; Deeper section: UC $356 \times 368 \times 129 ; h_{\mathrm{s}} / h_{\mathrm{d}}=0.1$

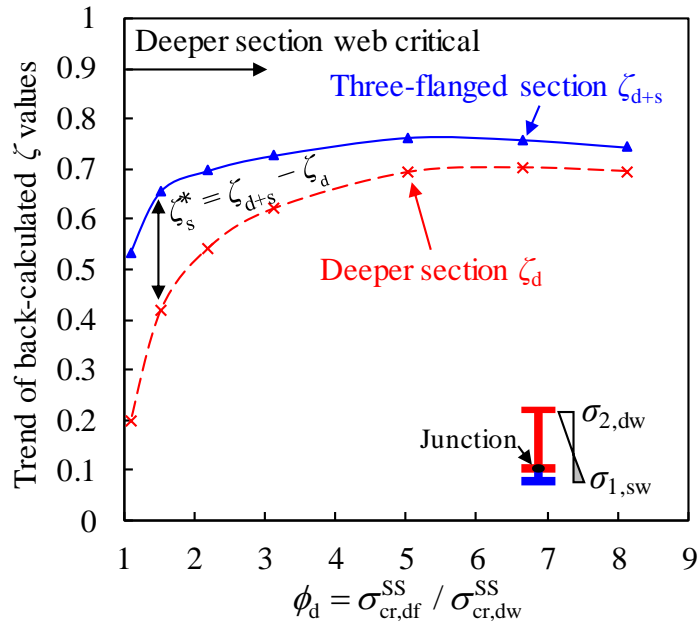

(b) Deeper section web critical $\left(\phi_{\mathrm{d}} \geq 1\right)$; Deeper section: S $460 \times 81.4 ; h_{\mathrm{s}} / h_{\mathrm{d}}=0.1$

Fig. 16 Example trends of back-calculated interaction coefficients for single deeper I-sections $\zeta_{\mathrm{d}}$ and corresponding three-flanged cross-sections $\zeta_{\mathrm{d}+\mathrm{s}}$ 


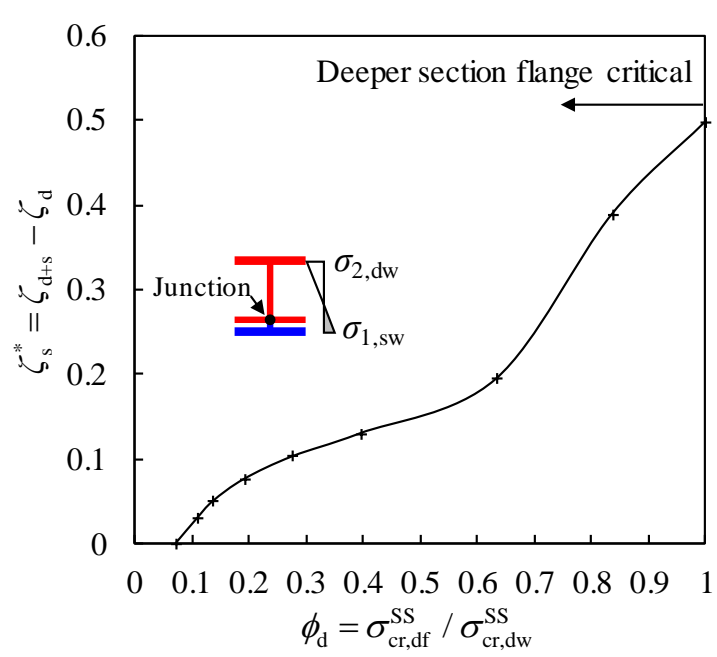

(a) Deeper section flange critical $\left(\phi_{\mathrm{d}}<1\right)$; Deeper section: UC $356 \times 368 \times 129 ; h_{\mathrm{s}} / h_{\mathrm{d}}=0.1$

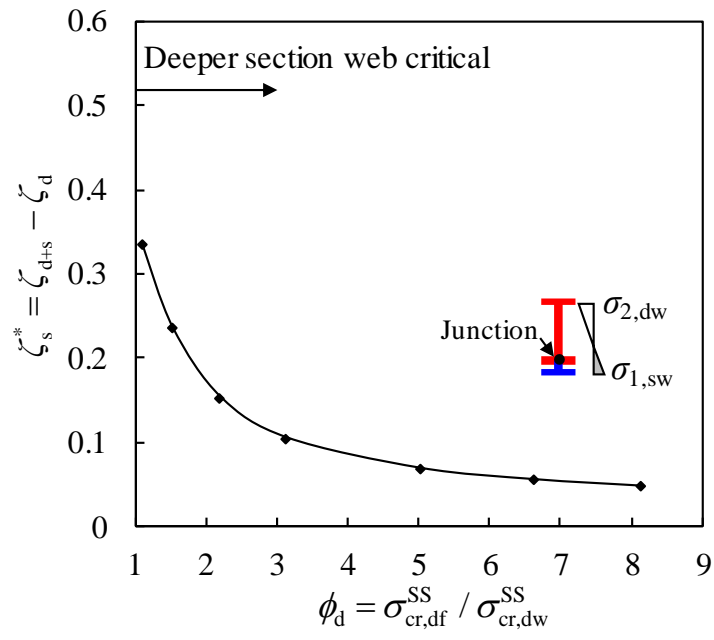

(b) Deeper section web critical $\left(\phi_{\mathrm{d}} \geq 1\right)$; Deeper section: $\mathrm{S} 460 \times 81.4 ; h_{\mathrm{S}} / h_{\mathrm{d}}=0.1$

Fig. 17 CUFSM results showing influence of shallower section on critical deeper section through interaction coefficient $\zeta_{\mathrm{s}}^{*}$, for deeper section critical scenarios in Case 2 


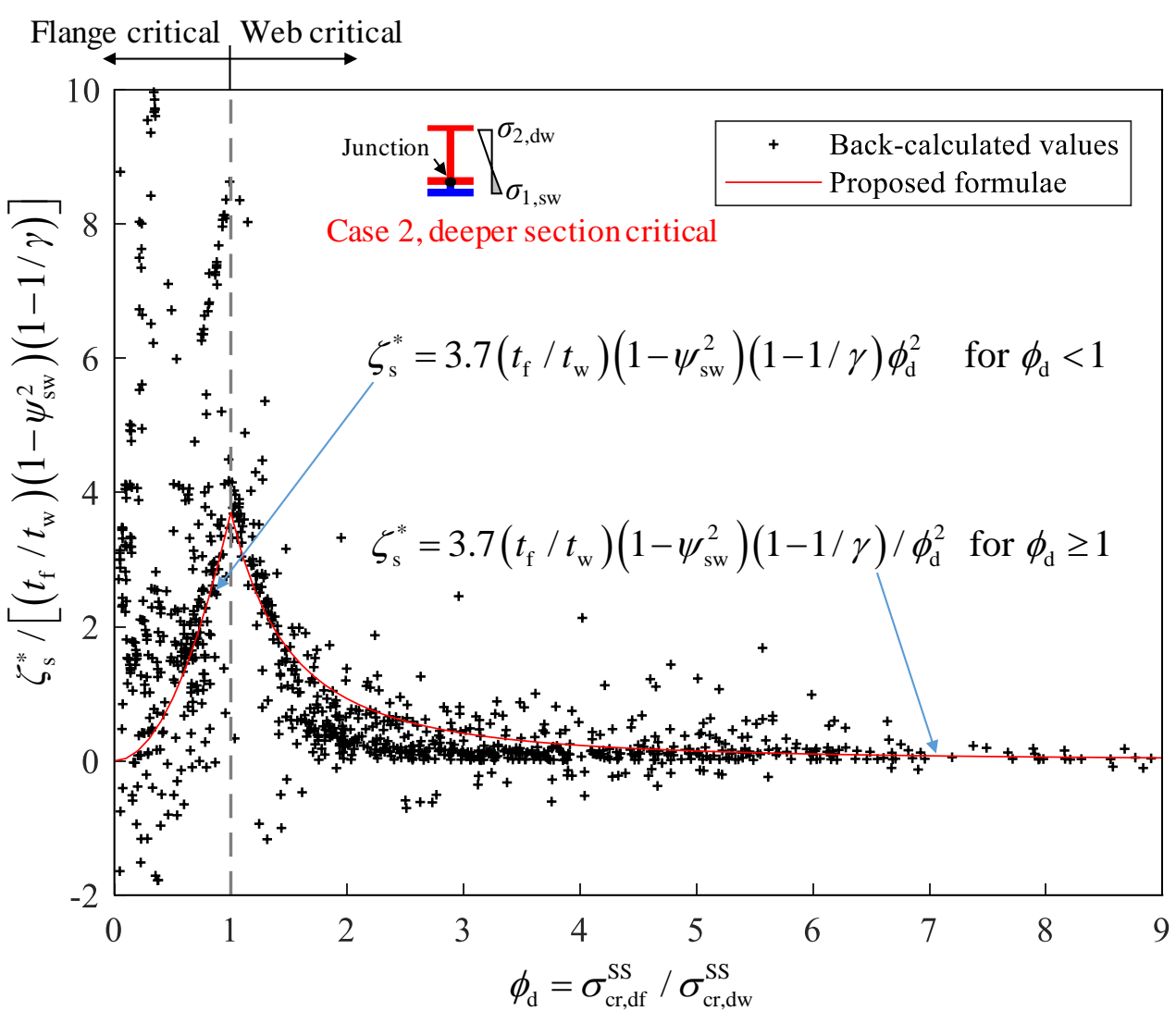

Fig. 18 Back-calculated normalised values of $\zeta_{\mathrm{s}}^{*}$ from CUFSM and proposed predictive equations for deeper section critical scenarios in Case 2 


\section{Stress distribution}

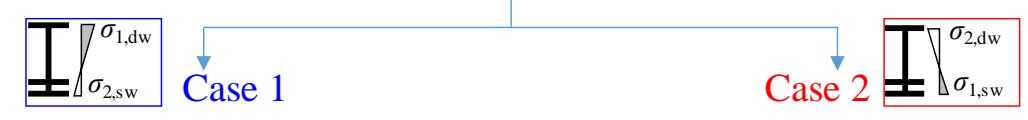

(Max. compression in deeper section) (Max. compression in shallower section)

Deeper section critical,

Calculate $\sigma_{\mathrm{cr}, \mathrm{d}}$ and $\sigma_{\mathrm{cr}, \mathrm{s}}$ calculate $\sigma_{\mathrm{cr}, \mathrm{d}}$

$$
\begin{aligned}
& \zeta_{\mathrm{d}+\mathrm{s}}=\zeta_{\mathrm{d}}, \text { hence } \\
& \sigma_{\mathrm{cr}, \mathrm{d}+\mathrm{s}}=\sigma_{\mathrm{cr}, \mathrm{d}} \\
& =\sigma_{\mathrm{cr}, \mathrm{dp}}^{\mathrm{SS}}+\zeta_{\mathrm{d}}\left(\sigma_{\mathrm{cr}, \mathrm{dp}}^{\mathrm{F}}-\sigma_{\mathrm{cr}, \mathrm{dp}}^{\mathrm{SS}}\right)
\end{aligned}
$$

$$
\begin{aligned}
\alpha_{\mathrm{cr}, \mathrm{d}} & =\sigma_{\mathrm{cr}, \mathrm{d}} / \psi_{\mathrm{sw}} \\
\alpha_{\mathrm{cr}, \mathrm{s}} & =\sigma_{\mathrm{cr}, \mathrm{s}} \\
\gamma & =\frac{\alpha_{\mathrm{cr}, \mathrm{s}}}{\alpha_{\mathrm{cr}, \mathrm{d}}}
\end{aligned}
$$

Shallower section critical

$$
\begin{aligned}
& \quad\left(\gamma<1, \alpha_{\mathrm{cr}, \mathrm{s}}<\alpha_{\downarrow}, \mathrm{cr,d}\right) \\
& \zeta_{\mathrm{d}+\mathrm{s}}=\zeta_{\mathrm{s}}, \text { hence } \\
& \sigma_{\mathrm{cr}, \mathrm{d}+\mathrm{s}}=\sigma_{\mathrm{cr}, \mathrm{s}} \\
& =\sigma_{\mathrm{cr}, \mathrm{sp}}^{\mathrm{ss}}+\zeta_{\mathrm{s}}\left(\sigma_{\mathrm{cr}, \mathrm{sp}}^{\mathrm{F}}-\sigma_{\mathrm{cr}, \mathrm{sp}}^{\mathrm{ss}}\right)
\end{aligned}
$$

\section{Deeper section critical}

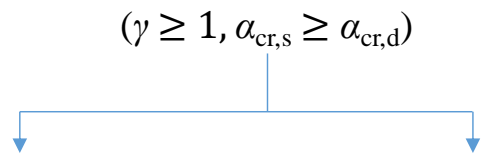

Flange critical, $\phi_{\mathrm{d}}<1$

Web critical, $\phi_{\mathrm{d}} \geq 1$

$$
\begin{gathered}
\zeta_{\mathrm{s}}^{*}=3.7 \frac{t_{\mathrm{f}}}{t_{\mathrm{w}}}\left(1-\psi_{\mathrm{sw}}^{2}\right)\left(1-\frac{1}{\gamma}\right) \phi_{\mathrm{d}}^{2} \quad \zeta_{\mathrm{s}}^{*}=3.7 \frac{t_{\mathrm{f}}}{t_{\mathrm{w}}}\left(1-\psi_{\mathrm{sw}}^{2}\right)\left(1-\frac{1}{\gamma}\right) / \phi_{\mathrm{d}}^{2} \\
\zeta_{\mathrm{d}+\mathrm{s}}=\zeta_{\mathrm{d}}+\zeta_{\mathrm{s}}^{*}, \text { but } 0 \leq \zeta_{\mathrm{d}+\mathrm{s}} \leq 1 \\
\sigma_{\mathrm{cr}, \mathrm{d}+\mathrm{s}}=\left[\sigma_{\mathrm{cr}, \mathrm{dp}}^{\mathrm{ss}}+\zeta_{\mathrm{d}+\mathrm{s}}\left(\sigma_{\mathrm{cr}, \mathrm{dp}}^{\mathrm{F}}-\sigma_{\mathrm{cr}, \mathrm{dp}}^{\mathrm{ss}}\right)\right] / \psi_{\mathrm{sw}}
\end{gathered}
$$

Fig. 19 Proposed framework for calculating the elastic local buckling stress of three-flanged cross-sections 


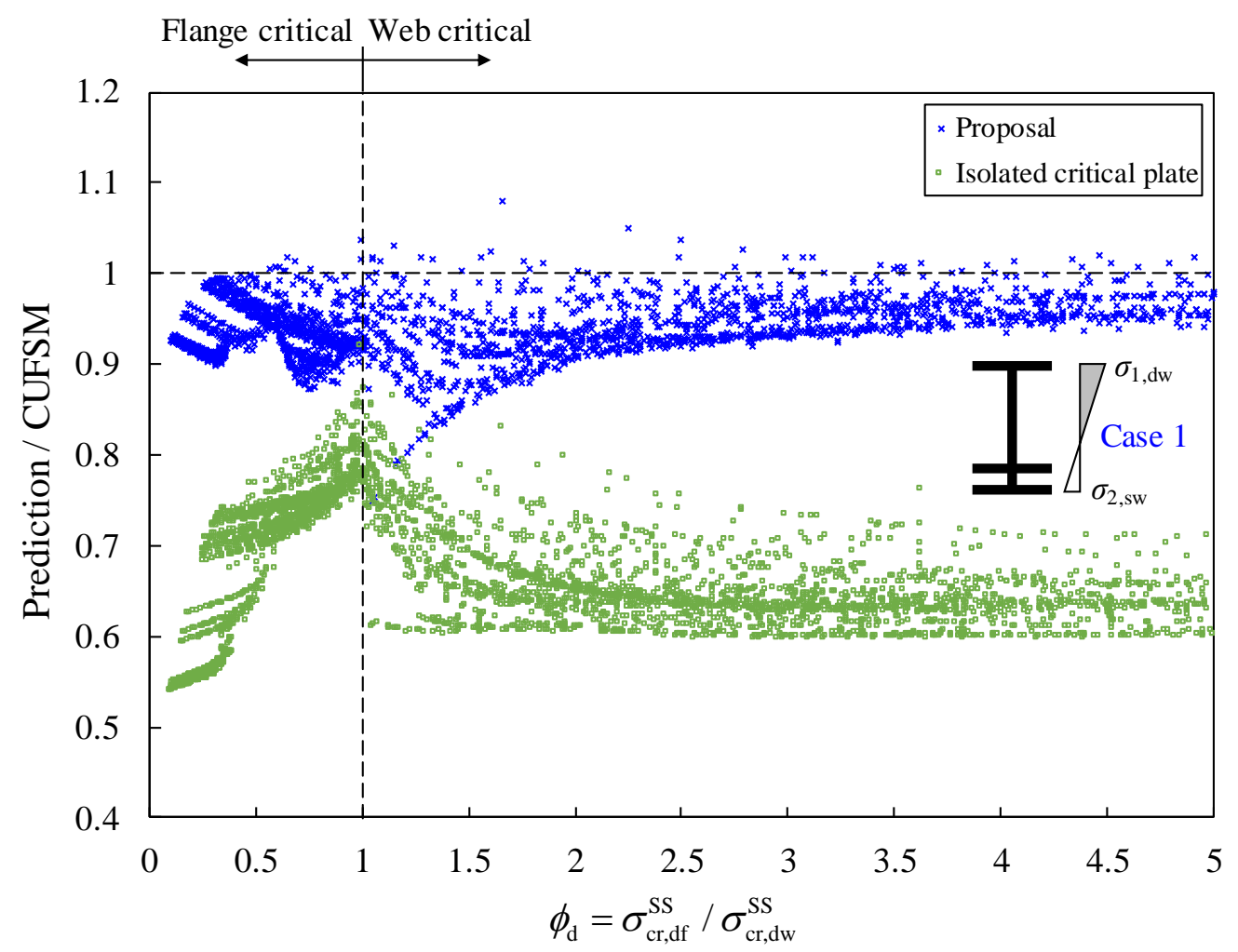

Fig. 20 Assessment of accuracy of predictions of elastic local buckling stresses of three-flanged cross-sections in Case 1 using proposed formulae and element-by-element approach (i.e. isolated critical plates having simplysupported boundary conditions along the adjoined edges) relative to numerical (CUFSM) results 


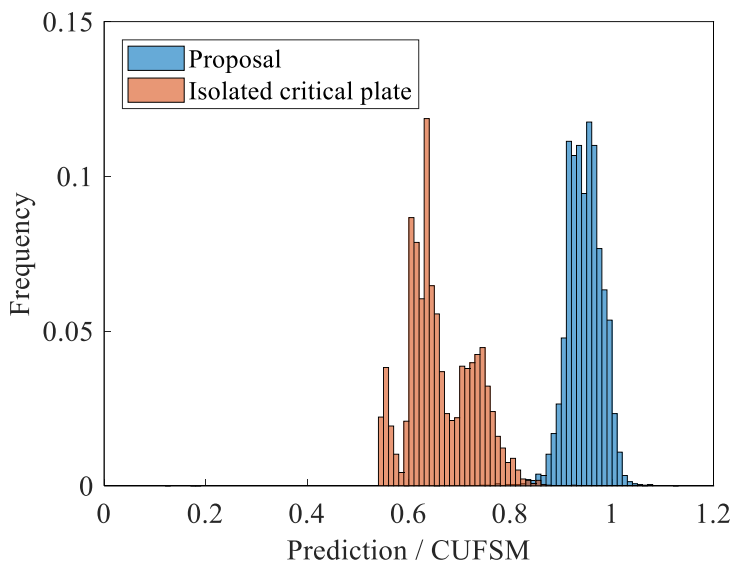

(a) Case 1

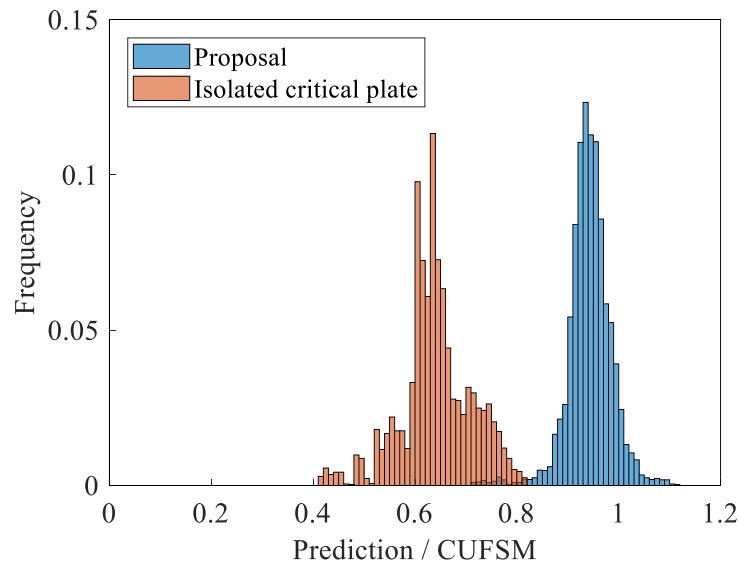

(b) Case 2

Fig. 21 Frequency distributions for predicted elastic local buckling stresses of three-flanged cross-sections in (a) Case 1 and (b) Case 2 using proposed formulae and element-by-element approach (i.e. isolated critical plates having simply-supported boundary conditions along the adjoined edges) relative to numerical (CUFSM) results 


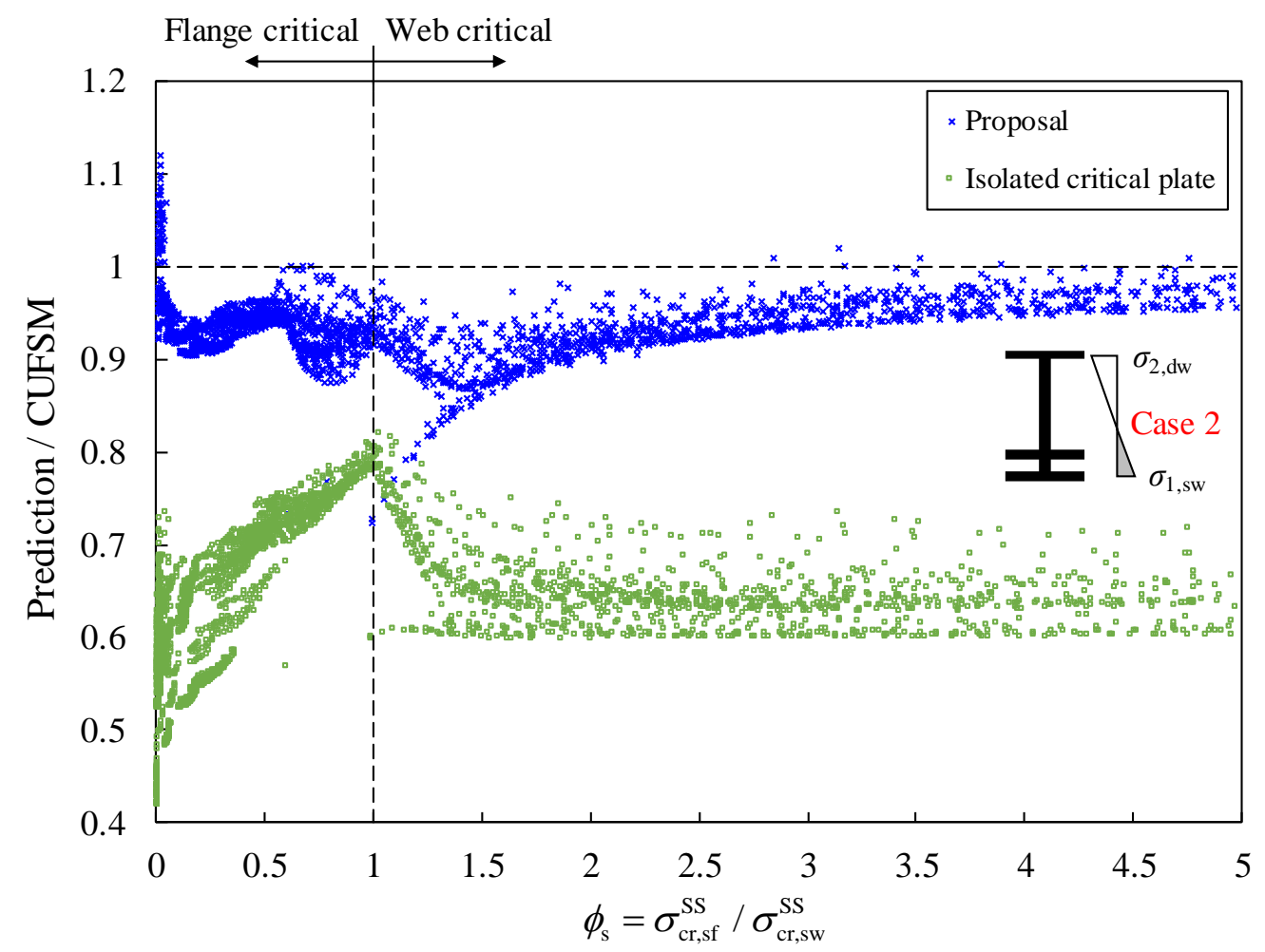

Fig. 22 Assessment of accuracy of predictions of elastic local buckling stresses of three-flanged cross-sections for shallower section critical scenarios in Case 2 using proposed formulae and element-by-element approach (i.e. isolated critical plates having simply-supported boundary conditions along the adjoined edges) relative to numerical (CUFSM) results 


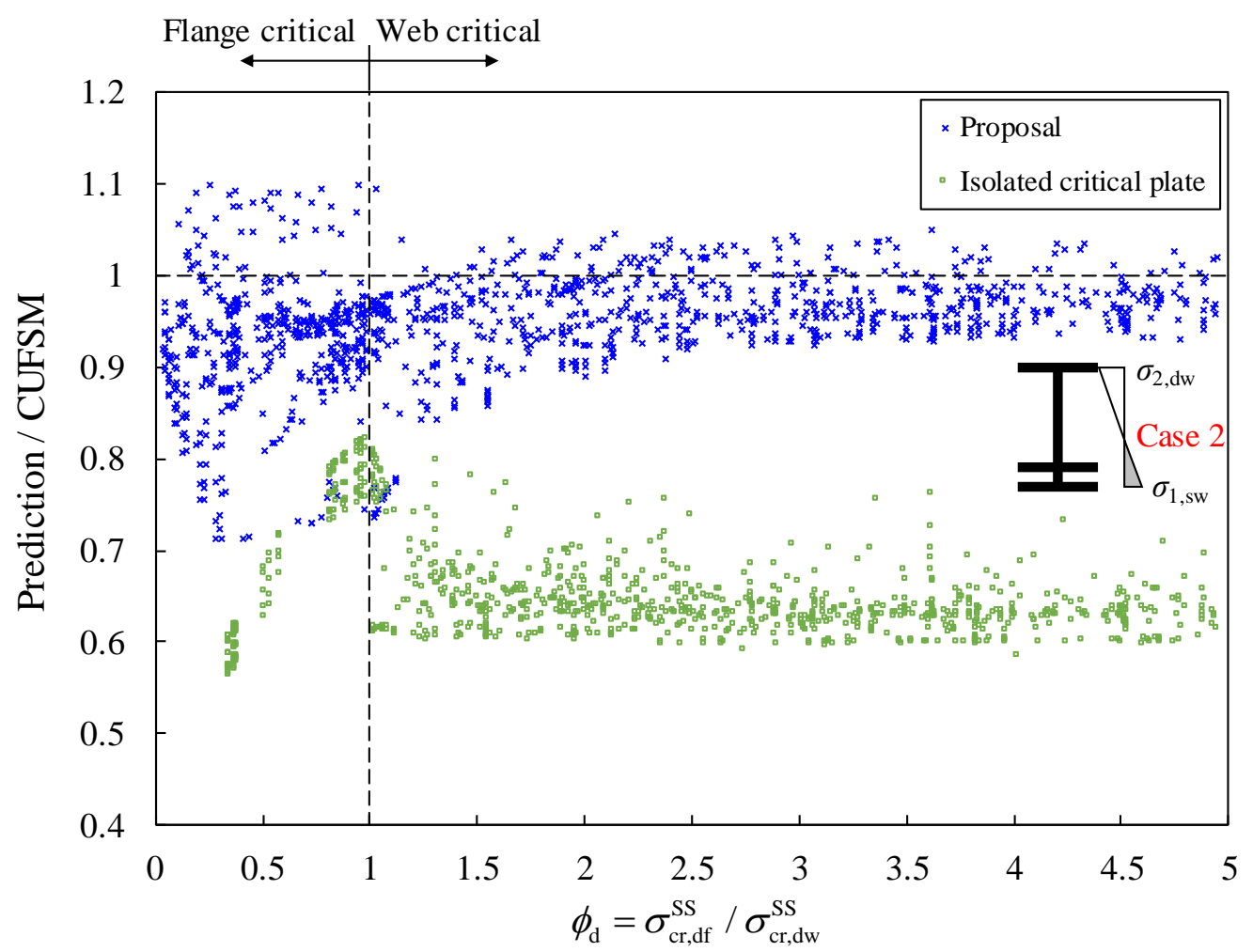

Fig. 23 Assessment of accuracy of predictions of elastic local buckling stresses of three-flanged cross-sections for deeper section critical scenarios in Case 2 using proposed formulae and element-by-element approach (i.e. isolated critical plates having simply-supported boundary conditions along the adjoined edges) relative to numerical (CUFSM) results 


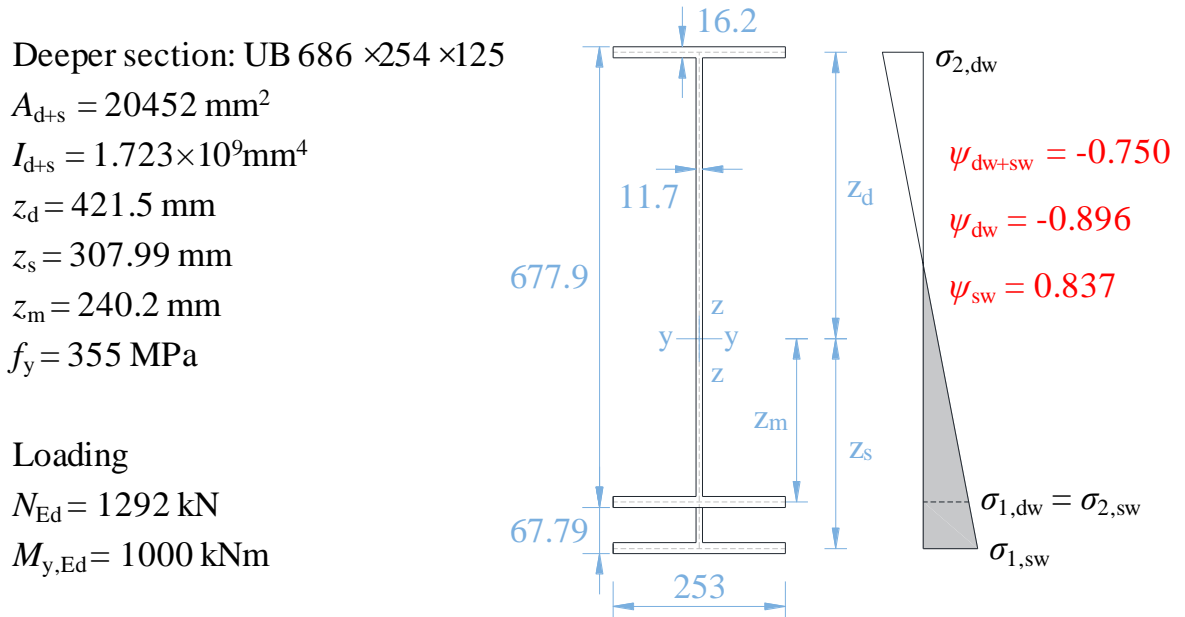

Fig. 24 Worked example: geometry and applied stress distribution in a three-flanged cross-section (all dimension in $\mathrm{mm}$ ) 


\section{Table 1}

Expressions for the buckling coefficient $k$ for internal and outstand plates with simply-supported (SS) boundary conditions along the adjoined edges - adopted from EN 1993-1-5 [28].

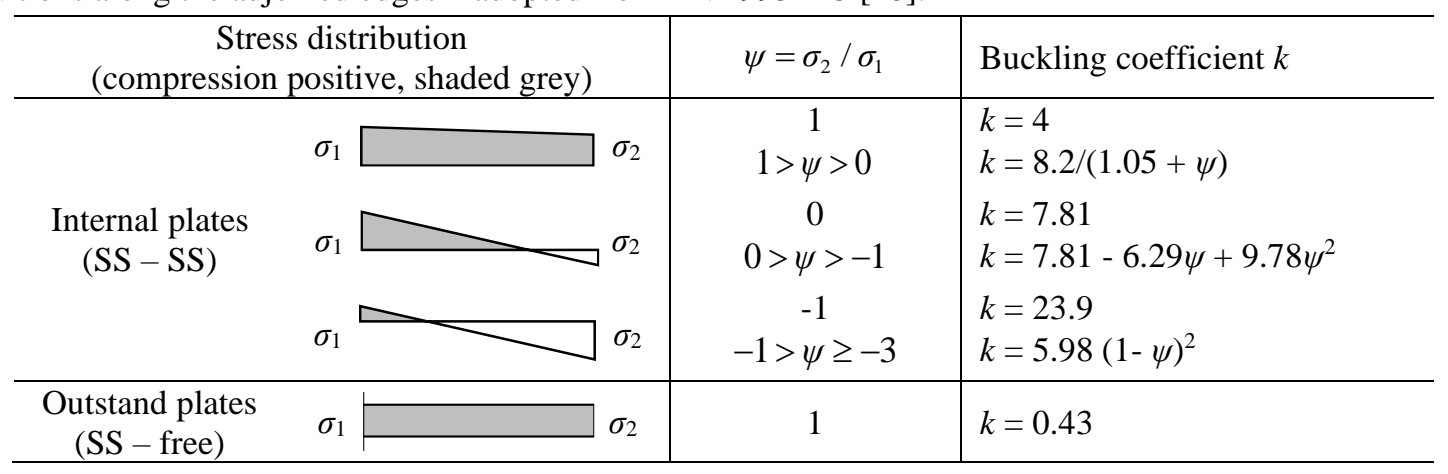




\section{Table 2}

Expressions for the buckling coefficient $k$ for internal and outstand plates with fixed boundary conditions along the adjoined edges - adopted from Gardner et al. [1].

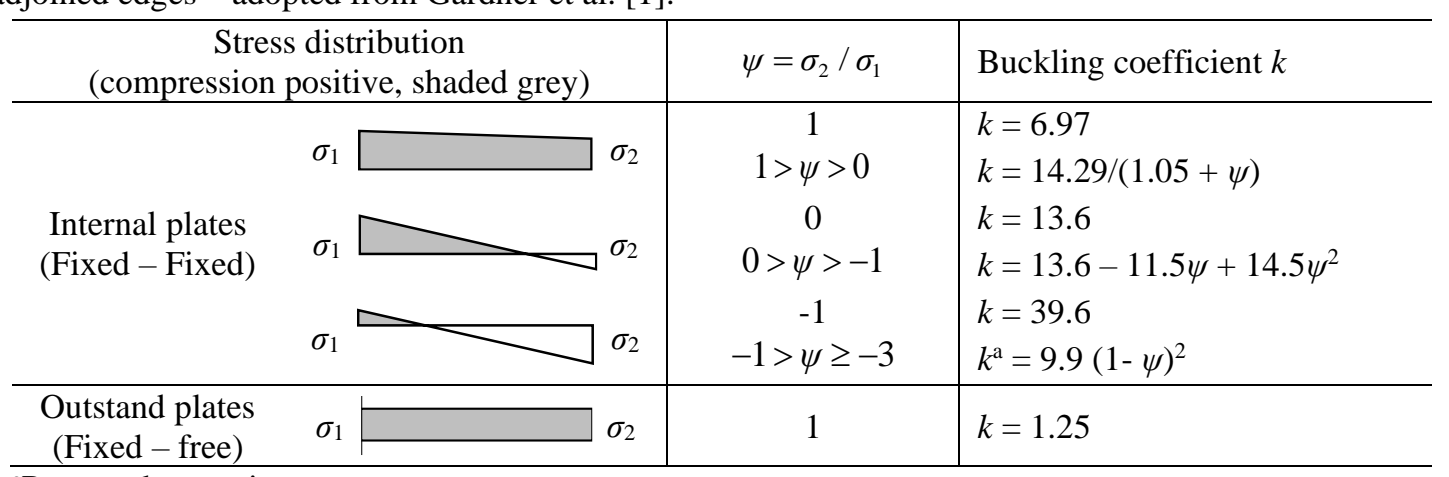

${ }^{\text {aProposed extension }}$ 


\section{Table 3}

Local buckling shapes of three-flanged cross-sections in Case 1 and Case 2. The orange coloured plate represents the critical element.

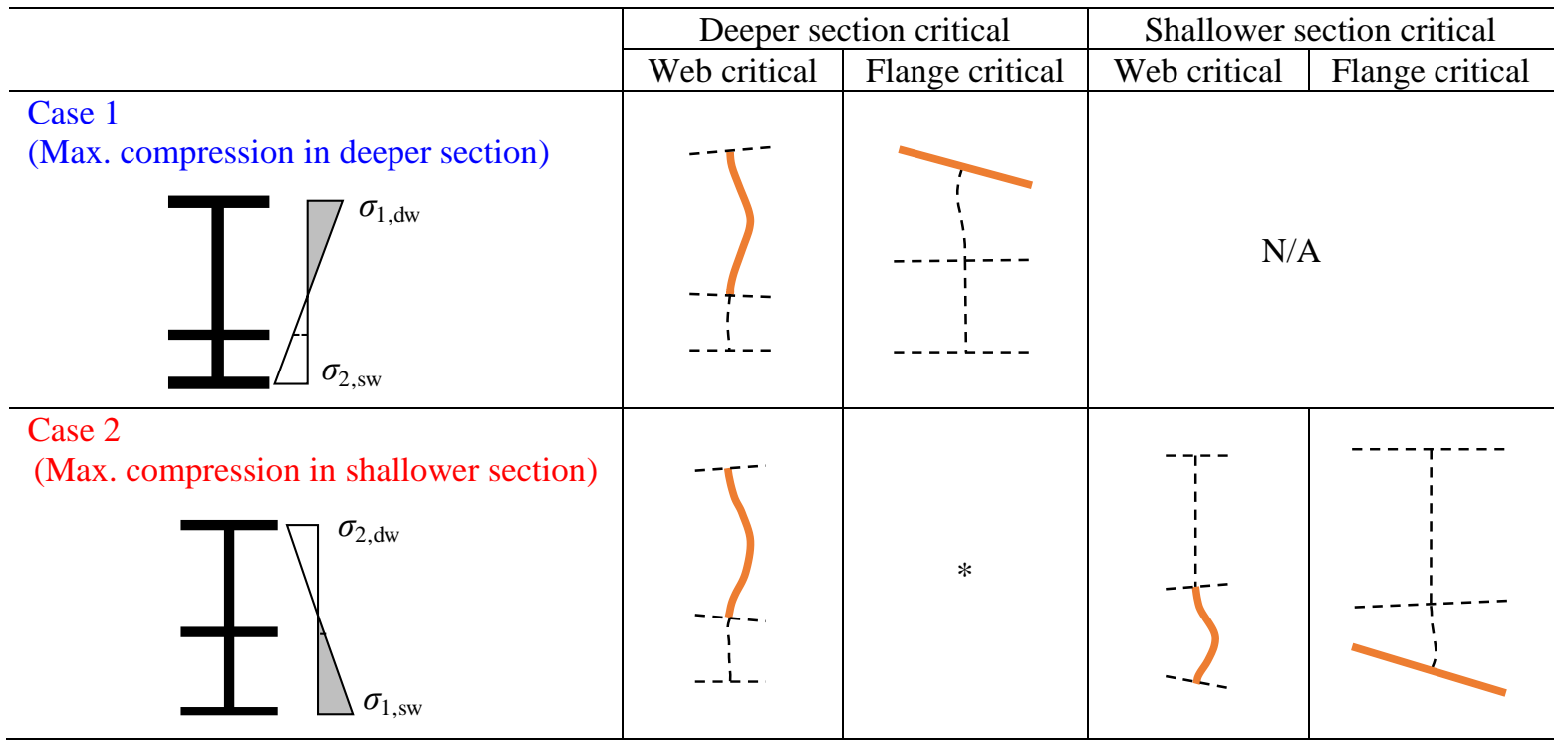

* Although the middle flange cannot be the critical plate element, this 'artificial' case is nonetheless considered as part of the calculation process - see Section 3.3 for further details. 


\section{Table 4}

Comparisons of the predicted elastic local buckling stresses of three-flanged cross-sections calculated using the proposed formulae and on an element-by-element basis (i.e. isolated critical plates having simply-supported boundary conditions along the adjoined edges) relative to numerical (CUFSM) results. For each of Cases 1 and 2 , the number of analysed cross-sections was as follows: 100 European and American I-sections $\times 5$ height ratios $\left(h_{\mathrm{s}} / h_{\mathrm{d}}\right) \times 9$ stress distributions $\left(\psi_{\mathrm{dw}+\mathrm{sw}}\right.$ values $)$.

\begin{tabular}{l|c|c|c}
\hline \multicolumn{2}{c|}{ Prediction/CUFSM } & Proposal & Isolated critical plate \\
\hline \multirow{4}{*}{ Case 1 } & Mean & 0.945 & 0.663 \\
& CoV & 0.036 & 0.099 \\
& Max & 1.080 & 0.920 \\
& Min & 0.749 & 0.540 \\
\hline \multirow{4}{*}{ Case 2 } & Mean & 0.943 & 0.641 \\
& CoV & 0.046 & 0.109 \\
& Max & 1.120 & 0.820 \\
& Min & 0.711 & 0.418 \\
\hline
\end{tabular}

